The University of Maine

\title{
DigitalCommons@UMaine
}

Earth Science Faculty Scholarship

Earth Sciences

7-27-2007

\section{Modeling Englacial Radar Attenuation at Siple Dome, West Antarctica, Using Ice Chemistry and Temperature Data}

Joseph A. MacGregor

Dale P.Winebrenner

Howard Conway

Kenichi Matsuoka

Paul Andrew Mayewski

University of Maine - Main, paul.mayewski@maine.edu

See next page for additional authors

Follow this and additional works at: https://digitalcommons.library.umaine.edu/ers_facpub

Part of the Earth Sciences Commons

\section{Repository Citation}

MacGregor, Joseph A.; Winebrenner, Dale P.; Conway, Howard; Matsuoka, Kenichi; Mayewski, Paul Andrew; and Clow, Gary D., "Modeling Englacial Radar Attenuation at Siple Dome, West Antarctica, Using Ice Chemistry and Temperature Data" (2007). Earth Science Faculty Scholarship. 62.

https://digitalcommons.library.umaine.edu/ers_facpub/62

This Article is brought to you for free and open access by DigitalCommons@UMaine. It has been accepted for inclusion in Earth Science Faculty Scholarship by an authorized administrator of DigitalCommons@UMaine. For more information, please contact

um.library.technical.services@maine.edu. 
Authors

Joseph A. MacGregor, Dale P. Winebrenner, Howard Conway, Kenichi Matsuoka, Paul Andrew Mayewski, and Gary D. Clow 


\title{
Modeling englacial radar attenuation at Siple Dome, West Antarctica, using ice chemistry and temperature data
}

\author{
Joseph A. MacGregor, ${ }^{1}$ Dale P. Winebrenner, ${ }^{2}$ Howard Conway, ${ }^{1}$ Kenichi Matsuoka, ${ }^{1}$ \\ Paul A. Mayewski, ${ }^{3}$ and Gary D. Clow ${ }^{4}$ \\ Received 25 October 2006; revised 16 March 2007; accepted 20 April 2007; published 27 July 2007.
}

[1] The radar reflectivity of an ice-sheet bed is a primary measurement for discriminating between thawed and frozen beds. Uncertainty in englacial radar attenuation and its spatial variation introduces corresponding uncertainty in estimates of basal reflectivity. Radar attenuation is proportional to ice conductivity, which depends on the concentrations of acid and sea-salt chloride and the temperature of the ice. We synthesize published conductivity measurements to specify an ice-conductivity model and find that some of the dielectric properties of ice at radar frequencies are not yet well constrained. Using depth profiles of ice-core chemistry and borehole temperature and an average of the experimental values for the dielectric properties, we calculate an attenuation rate profile for Siple Dome, West Antarctica. The depth-averaged modeled attenuation rate at Siple Dome $\left(20.0 \pm 5.7 \mathrm{~dB} \mathrm{~km}^{-1}\right)$ is somewhat lower than the value derived from radar profiles $\left(25.3 \pm 1.1 \mathrm{~dB} \mathrm{~km}^{-1}\right)$. Pending more experimental data on the dielectric properties of ice, we can match the modeled and radar-derived attenuation rates by an adjustment to the value for the pure ice conductivity that is within the range of reported values. Alternatively, using the pure ice dielectric properties derived from the most extensive single data set, the modeled depth-averaged attenuation rate is $24.0 \pm$ $2.2 \mathrm{~dB} \mathrm{~km}^{-1}$. This work shows how to calculate englacial radar attenuation using ice chemistry and temperature data and establishes a basis for mapping spatial variations in radar attenuation across an ice sheet.

Citation: MacGregor, J. A., D. P. Winebrenner, H. Conway, K. Matsuoka, P. A. Mayewski, and G. D. Clow (2007), Modeling englacial radar attenuation at Siple Dome, West Antarctica, using ice chemistry and temperature data, J. Geophys. Res., 112, F03008, doi:10.1029/2006JF000717.

\section{Introduction}

[2] Radio-echo sounding is a proven tool for characterizing the geometry, internal structure and subglacial environment of ice sheets and glaciers [Bogorodsky et al., 1985]. The basal echo intensity is of special interest because it can be diagnostic of thawed/frozen conditions at the bed. However, the basal echo intensity depends not only on the dielectric properties and roughness of the basal interface but also on the characteristics of the radar system, power losses from scattering, birefringence, geometric spreading and attenuation within the overlying ice. It is therefore necessary to account for those system characteristics and englacial

\footnotetext{
${ }^{1}$ Department of Earth and Space Sciences, University of Washington, Seattle, Washington, USA.

${ }^{2}$ Polar Science Center, Applied Physics Laboratory, University of Washington, Seattle, Washington, USA.

${ }^{3}$ Climate Change Institute, University of Maine at Orono, Orono, Maine, USA.

${ }^{4}$ U.S. Geological Survey, Lakewood, Colorado, USA.

Copyright 2007 by the American Geophysical Union. 0148-0227/07/2006JF000717
}

power losses, especially attenuation, to calculate the basal reflectivity.

[3] Relatively little is known about englacial attenuation and its spatial variation. Here we investigate power losses caused by dielectric absorption. Previous studies have accounted for attenuation either by making measurements over an ice shelf where the theoretical reflectivity at the icewater interface is known [e.g., Shabtaie et al., 1987; Bentley et al., 1998], empirically [e.g., Gades et al., 2000] or by using a temperature-attenuation relationship [e.g., Peters et al., 2005]. Corr et al. [1993] interpreted differences in radar-derived attenuation in two Antarctic ice shelves to be caused by differences in impurity concentrations. Miners et al. [2002] and Eisen et al. [2003] included attenuation in modeling studies of englacial reflections, but these studies focused on matching reflections and ice-core data rather than attenuation.

[4] Englacial attenuation is proportional to electrical conductivity. Frequencies typically used to sound deep ice range from 1 to $300 \mathrm{MHz}$ [e.g., Gogineni et al., 1998; Gades et al., 2000; Matsuoka et al., 2002] and frequencies less than $10 \mathrm{MHz}$ are particularly well suited to measuring attenuation [Winebrenner et al., 2003]. This frequency range is within the ac conductivity "plateau", which is above the 
Debye dispersion ( $\sim 0.01 \mathrm{MHz})$ and below the low-frequency tail of the infrared resonance that begins at $\sim 5 \mathrm{GHz}$ [Moore and Fujita, 1993]. The high-frequency $(0.1-300 \mathrm{MHz})$ conductivity of ice depends on its impurity concentrations and its temperature.

[5] Observations from Siple Dome, West Antarctica $\left(81.7^{\circ} \mathrm{S}, 148.8^{\circ} \mathrm{W}\right)$, provide a unique opportunity to test a model of radar attenuation. Siple Dome has been the site of extensive glaciological investigations, including a 1004-m ice core to the bed [Gow and Engelhardt, 2000]. A borehole temperature profile and measurements of major-ion concentrations along most of the ice core provide the data necessary to model of attenuation. In addition, Winebrenner et al. [2003] used ground-based radar profiles from Jacobel et al. [1996] to calculate englacial radar attenuation at Siple Dome. Ice thickness varies by several hundred meters across the dome. On the basis of assumptions of constant basal reflectivity and depth-averaged attenuation along the radar profiles, they calculated a depth-averaged attenuation rate of $25.9 \mathrm{~dB} \mathrm{~km}^{-1}$.

[6] Here we use published conductivity measurements to specify a conductivity model that depends on the impurity concentrations and temperature of the ice. We then use depth profiles of major-ion concentrations and temperature as inputs into the ice-conductivity model and calculate an attenuation rate profile for Siple Dome. Finally, we compare the depth-averaged modeled attenuation rate to the value derived from radar profiling data.

\section{High-Frequency Conductivity of Ice}

[7] Methods for measuring the high-frequency conductivity of ice cores, summarized by Wolff [2000], include dielectric profiling (DEP) [e.g., Moore et al., 1992a], complex conductivity measurements (CCM) and ac electrical conductivity measurements (AC-ECM) [e.g., Sugiyama et $a l ., 2000]$. These measurements are typically made at constant temperature on extracted ice cores. However, the high-frequency conductivity of ice consists of several components that have separate temperature dependencies; measurements of conductivity at a constant temperature are not sufficient to describe the englacial conductivity of ice sheets that are not isothermal. Below we describe a conductivity model that allows for the depth variations of ice chemistry and temperature that are typically observed in ice sheets.

\subsection{Conductivity Model}

[8] The high-frequency conductivity of pure ice is due to the polarization of individual $\mathrm{H}_{2} \mathrm{O}$ molecules, ionic defects $\left(\mathrm{H}_{3} \mathrm{O}^{+}\right.$and $\left.\mathrm{OH}^{-}\right)$and Bjerrum defects in the presence of an alternating electric field [Petrenko and Whitworth, 1999]. The high-frequency conductivity of meteoric polar ice is also linearly dependent on its molar concentrations of acid $\left(\mathrm{H}^{+}\right)$, sea-salt chloride ( $\left.\mathrm{ss} \mathrm{Cl}^{-}\right)$and ammonium $\left(\mathrm{NH}_{4}^{+}\right)$[e.g., Moore and Fujita, 1993; Petrenko and Whitworth, 1999; Fujita et al., 2000]. The conductivity contribution of pure ice and each of these impurities have separate Arrheniusform temperature dependencies. Conduction mechanisms in ice are not yet fully understood [Wolff et al., 1997; Wolff, 2000]. The $\mathrm{H}^{+}$contribution is generally attributed to con- centrations of acid in quasi-liquid layers at grain boundaries [Moore and Fujita, 1993; Wolff et al., 1997], although acids may also be present outside the grain boundaries [Cullen and Baker, 2001; Barnes and Wolff, 2004]. The ss $\mathrm{Cl}^{-}$ contribution is probably caused by $\mathrm{ss}^{-}$ions that form Bjerrum-L defects [Moore et al., 1992a; Moore and Fujita, 1993], while the ammonium contribution is probably caused by $\mathrm{NH}_{4}^{+}$ions that form Bjerrum-D defects [Moore et al., 1994; Wolff et al., 1997].

[9] We assume that the total conductivity $\sigma$ at Siple Dome can be represented by an empirical function of the form [e.g., Corr et al., 1993]

$$
\begin{aligned}
\sigma= & \sigma_{\text {pure }} \exp \left[\frac{E_{\text {pure }}}{k}\left(\frac{1}{T_{r}}-\frac{1}{T}\right)\right]+\mu_{\mathrm{H}^{+}}\left[\mathrm{H}^{+}\right] \exp \left[\frac{E_{\mathrm{H}^{+}}}{k}\left(\frac{1}{T_{r}}-\frac{1}{T}\right)\right] \\
& +\mu_{\mathrm{ss} \mathrm{Cl}^{-}}\left[\mathrm{ss} \mathrm{Cl}^{-}\right] \exp \left[\frac{E_{\mathrm{ssCl}^{-}}}{k}\left(\frac{1}{T_{r}}-\frac{1}{T}\right)\right]
\end{aligned}
$$

where $\sigma_{\text {pure }}$ is the pure ice conductivity, $\mu_{\mathrm{H}+}$ and $\mu_{\mathrm{ss} \mathrm{Cl}^{-}}$are molar conductivities, $E_{\text {pure }}, E_{\mathrm{H}+}$ and $E_{\mathrm{ss} \mathrm{Cl}^{-}}$are activation energies, $k$ is Boltzmann's constant, $T$ is temperature in Kelvin and $T_{r}=251 \mathrm{~K}$ is a reference temperature.

[10] Although $\left[\mathrm{NH}_{4}^{+}\right]$is high in Greenland, it is generally small in meteoric ice in Antarctica [Legrand and Mayewski, 1997]. Measurements from the 150-m 1994 Siple Dome core indicate that the mean value of $\left[\mathrm{NH}_{4}^{+}\right]$is only $0.13 \mu \mathrm{M}$ [Mayewski et al., 1995], where $\mathrm{M}=\mathrm{mol} \mathrm{L}^{-1}$. Moore et al. [1994] found that the molar conductivity of $\mathrm{NH}_{4}^{+}$at $-15^{\circ} \mathrm{C}$ is $1.0 \mathrm{~S} \mathrm{~m}^{-1} \mathrm{M}^{-1}$. At Siple Dome, the product of $\left[\mathrm{NH}_{4}^{+}\right]$and its molar conductivity is generally more than an order of magnitude smaller than that for $\mathrm{H}^{+}$or $\mathrm{ss}^{-}$, so we ignore its contribution to conductivity in this study.

[11] Conductivity increases with firn density but its density dependence is not yet well known [Barnes et al., 2002]. In the upper firn layer, we correct each conductivity component in (1) for density using a conductivity-density model suggested by Barnes et al. [2002], which includes a Looyenga mixing model for the pure ice and $\mathrm{ss} \mathrm{Cl}^{-}$ components and a percolation model for the $\mathrm{H}^{+}$component. While Barnes et al. [2002] focused on the conductivitydensity relationship of $\mathrm{H}_{2} \mathrm{SO}_{4}$, we assume that the percolation model is valid for all acids (section 2.3.2).

\subsection{Synthesis of Experimental Data}

\subsubsection{Reported Dielectric Properties}

[12] Table 1 shows reported experimental values for each of the dielectric properties in (1) and the mean and standard deviation of each dielectric property. Here we use the mean and standard deviation of the dielectric properties to calculate the total conductivity and its uncertainty. References given in Table 1 are those that originally reported the measurements; the footnotes discuss any adjustments that have been made to the original reported values. Activation energies in Table 1 are only reported from experiments that measured conductivity over a range of temperatures.

[13] Several conductivity experiments are not reported in Table 1. We do not use values of the pure ice dielectric properties derived from experiments at microwave frequencies because those data may be affected by the lowfrequency tail of the infrared resonances. We include 
Table 1. Observed, Mean, and Standard Deviation of the Dielectric Properties Used in the Conductivity Model Given in Equation (1) ${ }^{\text {a }}$

\begin{tabular}{|c|c|c|c|c|c|c|c|c|c|}
\hline Reference & Ice Type & $\begin{array}{c}\text { Temperature, } \\
\mathrm{K}\end{array}$ & $\begin{array}{c}\text { Frequency, } \\
\mathrm{MHz}\end{array}$ & $\begin{array}{c}E_{\text {pure }}, \\
\mathrm{eV}\end{array}$ & $\begin{array}{l}E_{\mathrm{H}+}, \\
\mathrm{eV}\end{array}$ & $\begin{array}{l}E_{\mathrm{sS} \mathrm{Cl}^{-}} \\
\mathrm{eV}\end{array}$ & $\begin{array}{c}\sigma_{\text {pure }} \\
\mu \mathrm{S} \mathrm{m}^{-1}\end{array}$ & $\begin{array}{c}\mu_{\mathrm{H}+} \\
\mathrm{S} \mathrm{m}^{-1} \mathrm{M}^{-1} \\
\end{array}$ & $\begin{array}{l}\mu_{\mathrm{ss} \mathrm{Cl-}}, \\
\mathrm{S} \mathrm{m}^{-1} \mathrm{M}^{-1}\end{array}$ \\
\hline 1 & lab-grown pure & $225-265$ & 0.02 & 0.61 & & $\ldots$ & 4.5 & . & .. \\
\hline 2 & lab-grown pure & $248-272$ & $35-60$ & $0.51 \pm 0.01^{\mathrm{b}}$ & $\ldots$ & $\ldots$ & $9.2 \pm 0.2^{\mathrm{b}}$ & & $\ldots$ \\
\hline 3 & lab-grown pure & $123-263$ & 0.1 & $0.585 \pm 0.024$ & & $\ldots$ & & & \\
\hline 4 & ice core & 251 & 0.1 & $\ldots$ & $\ldots$ & $\ldots$ & $(12.7 \pm 0.3)^{\mathrm{c}}$ & $2.57 \pm 0.09^{\mathrm{d}}$ & $0.43 \pm 0.01^{\mathrm{e}}$ \\
\hline 5 & lab-grown doped & $243-268$ & 9700 & $\ldots$ & 0.195 & $\ldots$ & $\ldots$ & $3.5 \pm 0.3$ & $\ldots$ \\
\hline 6 & ice core & $203-273$ & 0.3 & $\ldots$ & $0.26 \pm 0.03$ & $0.19 \pm 0.02$ & .. & $\ldots$ & .. \\
\hline 7 & ice core & 251 & 0.3 & $\ldots$ & $\ldots$ & $\ldots$ & $(6.1 \pm 0.6)^{\mathrm{f}}$ & $3.66 \pm 0.16^{\mathrm{g}}$ & $\ldots$ \\
\hline 8 & ice core & 258 & 0.3 & $\ldots$ & $\ldots$ & $\ldots$ & & $3.5 \pm 0.5^{\mathrm{h}}$ & $\ldots$ \\
\hline 9 & lab-grown doped & $240-264$ & $0.1-5$ & $0.51 \pm 0.01^{\mathrm{i}}$ & $0.20 \pm 0.01$ & $\ldots$ & $6.0 \pm 0.1^{\mathrm{i}}$ & $2.3 \pm 1.0$ & . \\
\hline 10 & lab-grown doped & $193-271$ & 5000 & $\ldots$ & $0.16^{\mathrm{j}}$ & $\ldots$ & $\ldots$ & $3.0^{\mathrm{k}}$ & \\
\hline 11 & ice core & 253 & 1 & $\ldots$ & $\ldots$ & $\ldots$ & & $3.1 \pm 0.7$ & \\
\hline 12 & ice core & 258 & 0.1 & $\ldots$ & $\ldots$ & $\ldots$ & $(4.9 \pm 1.0)^{\mathrm{f}}$ & $3.8^{1}$ & $(1.0)^{\mathrm{m}}$ \\
\hline This study & $\begin{array}{l}\text { Mean and } \\
\text { standard deviation }\end{array}$ & & & $0.55 \pm 0.05$ & $0.20 \pm 0.04$ & $0.19 \pm 0.02$ & $\begin{array}{l}(7.2 \pm 3.1)^{\mathrm{n}} \\
6.6 \pm 2.4^{\mathrm{p}}\end{array}$ & $3.2 \pm 0.5$ & $0.43 \pm 0.07^{\circ}$ \\
\hline
\end{tabular}

${ }^{\mathrm{a}}$ The reference temperature used throughout this table and study is $251 \mathrm{~K}$; values reported at a different reference temperature were adjusted to our reference temperature using the mean activation energies. References are: 1. Camplin and Glen [1973]; 2. Johari and Charette [1975]; 3. Takei and Maeno [1987]; 4. Moore et al. [1989]; 5. Fujita et al. [1992]; 6. Moore et al. [1992a]; 7. Moore et al. [1992b]; 8. Moore et al. [1994]; 9. Matsuoka et al. [1996]; 10. Matsuoka et al. [1997a]; 11. Sugiyama et al. [2000]; 12. Barnes et al. [2002]. Reasons for values in parentheses are explained in their respective footnotes.

${ }^{b}$ Value is calculated using a nonlinear least-squares fit to the single crystal data at 35 and $60 \mathrm{MHz}$ from Figures 2 and 3 of Johari and Charette [1975]; uncertainties given are the $99 \%$ confidence bounds on this fit and the fraction of explained variance is 0.97 .

${ }^{c}$ Corr et al. [1993] argued that organic acids contributed $8 \mu \mathrm{S} \mathrm{m}^{-1}$ to the constant value of the DEP regression reported by Moore et al. [1989]. However, Moore et al. [1989] reported "very good agreement" between $\left[\mathrm{H}^{+}\right]$values from acid titration measurements and those calculated from a charge balance that did not include organic acids, so it is unlikely that large concentrations of organic acids altered the impurity concentrations used in their DEP regression (section 3.2). The reported constant value of the DEP regression is interpreted as $\sigma_{\text {pure }}$ but ignored in the calculation of its mean and standard deviation.

"Value is adjusted from $1.43 \pm 0.05 \mathrm{~S} \mathrm{~m}^{-1} \mathrm{M}^{-1}$ by Moore and Fujita [1993], who reevaluated the values of $\left[\mathrm{H}^{+}\right]$used by considering the "effective" $\left[\mathrm{H}^{+}\right]$ of $\mathrm{H}_{2} \mathrm{SO}_{4}$ in the ice (section 2.3.2).

${ }^{\mathrm{e}}$ Value is adjusted from $0.39 \pm 0.01 \mathrm{~S} \mathrm{~m}^{-1} \mathrm{M}^{-1}$ by Moore et al. [1992a], who converted $\mu_{\text {salt }}$ to $\mu_{\text {ss } \mathrm{Cl}^{-}}$.

${ }^{\mathrm{f}}$ The reported constant value of the DEP regression is interpreted as $\sigma_{\text {pure }}$ but ignored in the calculation of its mean and standard deviation.

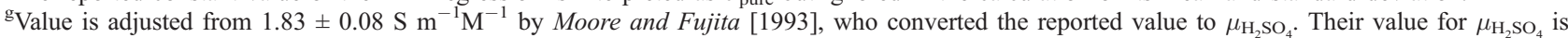
reported here as $\mu_{\mathrm{H}+}$ (section 2.3.2).

${ }^{\mathrm{h}}$ Mean and standard deviation of four values is reported for four separate depth ranges in the GRIP core.

${ }^{\mathrm{i}}$ Value is calculated using a nonlinear least-squares fit to the mean conductivity of two pure ice samples between 0.5 and $1.0 \mathrm{MHz}$; uncertainties given are the $99 \%$ confidence bounds on this fit and the fraction of explained variance is 0.98 .

${ }^{\mathrm{j}}$ This is mean of values of $E_{\mathrm{H}_{2} \mathrm{SO}_{4}}$ and $E_{\mathrm{HCl}}$.

${ }^{\mathrm{k}}$ This is mean of values of $\mu_{\mathrm{H}_{2} \mathrm{SO}_{4}}$ and $\mu_{\mathrm{HCl}}$.

${ }^{1}$ Barnes et al. [2002] reported values for the molar conductivities of $\mathrm{H}_{2} \mathrm{SO}_{4}$ and $\mathrm{HCl}$, but $\mathrm{H}_{2} \mathrm{SO}_{4}$ was the dominant impurity. Their value for $\mu_{\mathrm{H}_{2} \mathrm{SO}_{4}}$ is reported here as $\mu_{\mathrm{H}^{+}}$(section 2.3.2).

${ }^{\mathrm{m}}$ Barnes et al. [2002] stated that their value for $\mu_{\mathrm{ss} \mathrm{Cl}^{-}}$is not "well established" because [ $\left.\mathrm{Na}^{+}\right]$is anticorrelated with the measured acid species. Therefore we do not use this value when calculating the mean and standard deviation of $\mu_{\mathrm{ss} \mathrm{Cl}^{-}}$.

${ }^{\mathrm{n}}$ Value is calculated using all reported values of $\sigma_{\text {pure. }}$

${ }^{\circ}$ Uncertainties for the dielectric properties reported by Moore et al. [1989] are small relative to the reported range of values, so in the absence of additional reliable values for $\mu_{\mathrm{ss} \mathrm{Cl}}$ - we note their reported uncertainty for $\mu_{\mathrm{ss} \mathrm{Cl}}\left(0.01 \mathrm{~S} \mathrm{~m}^{-1} \mathrm{M}^{-1}\right)$ is likely an underestimate of its true uncertainty and assign $\mu_{\mathrm{ss} \mathrm{Cl}}$ the same relative uncertainty as $\mu_{\mathrm{H}^{+}}(16 \%)$.

${ }^{\mathrm{p}}$ We interpreted the constant values from DEP regression as $\sigma_{\text {pure }}$ (references 4,7 , and 12). However, these values may include contributions from unknown chemical species that contribute to the conductivity measured by DEP. Thus these values may overestimate $\sigma_{\text {pure }}$ and we do not include them in this preferred calculation of its mean and standard deviation.

dielectric properties of the $\mathrm{H}^{+}$component from microwave experiments because it is not dispersive, but we exclude microwave dielectric properties of the $\mathrm{ss}^{-}$component because it is dispersive [Moore and Fujita, 1993]. Temperature-dependent phenomena present at microwave frequencies may also be present at radar frequencies and are considered in sections 6.2.2 and 6.2.3.

[14] Figure 1 shows the contributions of pure ice, $\mathrm{H}^{+}$and ss $\mathrm{Cl}^{-}$components to the conductivity model given in (1) for a typical range of ice-sheet temperatures. The values for $\left[\mathrm{H}^{+}\right]$and $\left[\mathrm{ss} \mathrm{Cl}^{-}\right]$used in Figure 1 are the mean values at Siple Dome (section 5.1). This figure shows that the pure ice component of conductivity dominates the total conductivity as the temperature approaches the melting point.

[15] Evans [1965] reported conductivity measurements made by Westphal on Greenland ice at frequencies from
$150 \mathrm{MHz}$ to $2.7 \mathrm{GHz}$. The Westphal data appear to be the source for the temperature-attenuation relationship at $150 \mathrm{MHz}$ given by Gudmandsen [1971]. However, the impurity concentrations of the samples used by Westphal are unknown [Moore and Fujita, 1993] and therefore these measurements are not included in Table 1 . The temperatureattenuation relationship given by Gudmandsen [1971] can be described using a nonlinear least-squares fit to a singleterm conductivity model of the form

$$
\sigma=\sigma_{0} \exp \left[\frac{E_{0}}{k}\left(\frac{1}{T_{r}}-\frac{1}{T}\right)\right]
$$

where $\sigma_{0}=15.4 \pm 1.4 \mu \mathrm{S} \mathrm{m}^{-1}$ and $E_{0}=0.33 \pm 0.03 \mathrm{eV}$. The uncertainties are the $99 \%$ confidence intervals, which are a measure of the precision of the fit rather than the accuracy 


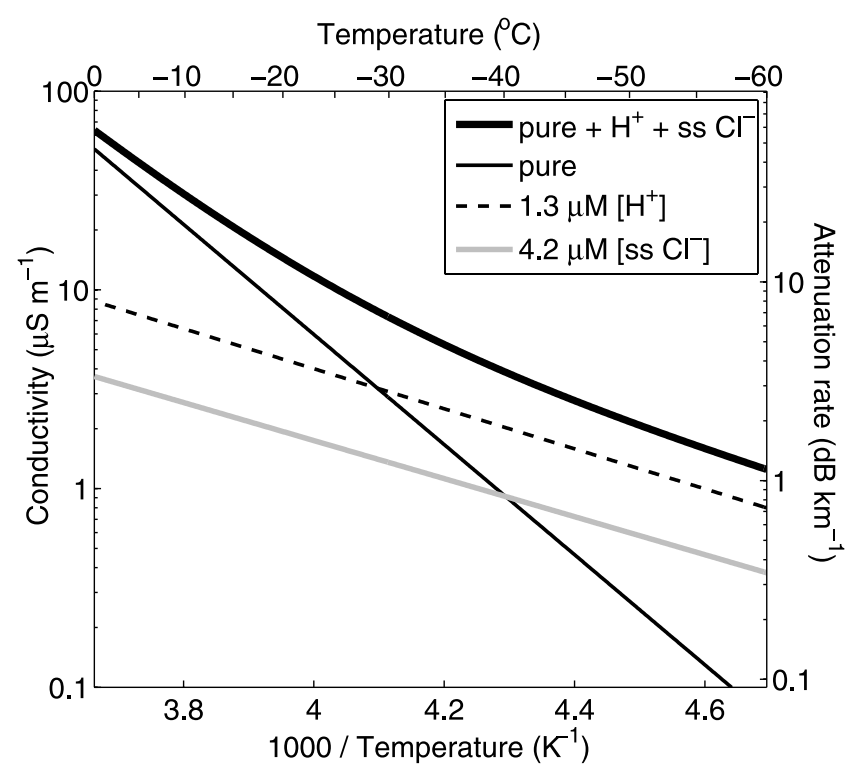

Figure 1. Contributions of pure ice, $\mathrm{H}^{+}$, and ss $\mathrm{Cl}^{-}$ components to the conductivity of ice as a function of inverse temperature. Values for $\left[\mathrm{H}^{+}\right]$and $\left[\mathrm{ss} \mathrm{Cl}^{-}\right]$are the mean values for Siple Dome (data discussed in section 5.1). For these concentrations, the pure ice component dominates the total conductivity at temperatures higher than $\sim-30^{\circ} \mathrm{C}$; higher impurity concentrations raise the temperature at which the pure ice component dominates. Equivalent attenuation rates are calculated using (10).

of the Gudmandsen [1971] relationship, which is not known. By subtracting the pure ice term in (1) from the fit to the Gudmandsen [1971] relationship, we can match that fit if the ice contains either $2.0 \pm 1.2 \mu \mathrm{M}$ of $\left[\mathrm{H}^{+}\right]$or $15.0 \pm 8.2 \mu \mathrm{M}$ of $\left[\mathrm{ss} \mathrm{Cl}^{-}\right]$, or a combination of lower concentrations of those impurities. However, the ice from which the Gudmandsen [1971] relationship was derived is from Greenland, where $\mathrm{NH}_{4}^{+}$may also be an important impurity.

[16] The mean temperature-conductivity relationship at Siple Dome, calculated using (1) and the mean values for $\left[\mathrm{H}^{+}\right]$and $\left[\mathrm{ss} \mathrm{Cl}^{-}\right]$, is well approximated by (2) using $\sigma_{0}=$ $12.7 \pm 0.6 \mu \mathrm{S} \mathrm{m}^{-1}$ and $E_{0}=0.42 \pm 0.02 \mathrm{eV}$. The differences between these best-fit values and those for the Gudmandsen [1971] relationship indicate the effect of different impurity concentrations on the temperature-conductivity relationship. A single temperature-conductivity relationship like (2) cannot capture the effect of separate temperature dependencies from distinct impurities. We therefore consider the Gudmandsen [1971] relationship inadequate for modeling conductivity versus depth, and thus attenuation, at Siple Dome.

\subsubsection{Model Mean and Uncertainty}

[17] We calculate the mean and standard deviation of measurements of the dielectric properties in (1) shown in Table 1 and ignore the reported experimental uncertainties in these calculations. We considered calculating values of the mean and uncertainty that are weighted by the uncertainties of the reported values [Bevington, 1969], but the reported uncertainties of most of the values in Table 1 are significantly smaller than the range of reported values for each dielectric property. Assuming that the same conduction mechanisms are present in all of the ice samples used in Table 1, this discrepancy suggests that most of the reported uncertainties in Table 1 underestimate the true uncertainty in their respective dielectric properties. However, recent work suggests that the conduction mechanism for different impurities also depends on both impurity concentration and grain structure of the ice [Barnes and Wolff, 2004]. This potential variability in the conduction mechanism may explain the large range of reported values of some of the $\mathrm{H}^{+}$ and $\mathrm{ss}^{-} \mathrm{Cl}^{-}$dielectric properties.

[18] Uncertainties in $\left[\mathrm{H}^{+}\right]$and $\left[\mathrm{ss} \mathrm{Cl}^{-}\right]$also affect uncertainty in the conductivity. The measurement uncertainties of the major-ion data are small, but we assign a constant uncertainty of $0.5 \mu \mathrm{M}$ to the calculated values of $\left[\mathrm{H}^{+}\right]$ and $\left[\mathrm{ss} \mathrm{Cl}^{-}\right]$(section 3.2). We assume that the dielectric properties do not covary and calculate the uncertainty in the total conductivity $\widetilde{\sigma}$ using standard error propagation techniques:

$$
\widetilde{\sigma}=\sqrt{\sum_{j=1}^{8} \widetilde{p}_{j}^{2}\left(\frac{\partial \sigma}{\partial p_{j}}\right)^{2}}
$$

where $p_{j}$ includes the six dielectric properties and two impurity concentrations, $\widetilde{p}_{j}$ is the standard deviation for the dielectric property (Table 1 ) or impurity concentration uncertainty $(0.5 \mu \mathrm{M})$ and $\sigma$ is the total conductivity given by (1). We report all uncertainties as $\pm 1 \widetilde{\sigma}$.

[19] Uncertainty in the activation energies affects the temperature dependence of the conductivity model, whereas uncertainty in the molar conductivities affects the impurityconcentration dependence. The relative uncertainty in the total conductivity $(\widetilde{\sigma} / \sigma)$ depends on the impurity concentrations and temperature. Values for $\tilde{\sigma} / \sigma$, calculated using the depth profiles of impurity concentrations and temperature at Siple Dome (section 5.1), range from 17 to $34 \%$; the mean value is $27 \%$.

[20] Because of the nonlinearity of (3), it is not possible to evaluate the contribution of each dielectric property or impurity concentration to $\tilde{\sigma} / \sigma$ independent of the contributions of the other dielectric properties and impurity concentrations. However, $\sigma_{\text {pure }}$ has the largest contribution to the uncertainty in the conductivity model. Assuming that $\sigma_{\text {pure }}$ is error-free, we set its standard deviation to zero and find that the mean value of $\tilde{\sigma} / \sigma$ decreases to $13 \%$. Using the same assumption for $E_{\text {pure, }}$, the mean value of $\tilde{\sigma} / \sigma$ decreases to $26 \%$, for $\left[\mathrm{H}^{+}\right]$it decreases to $25 \%$ and for the remaining dielectric properties and $\left[\mathrm{ss} \mathrm{Cl}^{-}\right]$it decreases by less than $1 \%$. Thus reduction in the uncertainty in $\sigma_{\text {pure }}$ most effectively reduces uncertainty in the conductivity model.

\subsection{Model Simplifications}

\subsubsection{Conductivity Dispersions}

[21] There is no evidence for significant dispersions in the $\mathrm{H}^{+}$component of conductivity in the high-frequency range but there is some evidence that the $\mathrm{ss}^{-}{ }^{-}$component of conductivity is dispersive, although its dispersion is not well 
quantified [Moore and Fujita, 1993]. Fujita et al. [2000] showed the frequency independence of the pure ice component of conductivity at frequencies below $300 \mathrm{MHz}$, which they calculated using an empirical relationship for conductivity at the high-frequency tail of the Debye relaxation and the low-frequency tail of the infrared resonance. Here we ignore possible conductivity dispersions and assume that the conductivity model is valid for the entire high-frequency range $(0.1-300 \mathrm{MHz})$.

\subsubsection{Conductivity of Different Acids}

[22] Several studies have found that $\mu_{\mathrm{H}^{+}}$is dependent on the acid species present [Matsuoka et al., 1997a; Fujita et al., 2000; Barnes et al., 2002]. Using DEP, Barnes et al. [2002] found that different acids have slightly different molar conductivities: $\mu_{\mathrm{H}_{2} \mathrm{SO}_{4}}=3.8 \mathrm{~S} \mathrm{~m}^{-1} \mathrm{M}^{-1}$ and $\mu_{\mathrm{HCl}}=$ $3.5 \mathrm{~S} \mathrm{~m}^{-1} \mathrm{M}^{-1}$, adjusted to $-22^{\circ} \mathrm{C}$ using $E_{\mathrm{H}+}=0.20 \mathrm{eV}$. The difference between these two values of $\mu_{\mathrm{H} 2 \mathrm{SO} 4}$ and $\mu_{\mathrm{HCl}}\left(0.3 \mathrm{~S} \mathrm{~m}^{-1} \mathrm{M}^{-1}\right)$ is smaller than the standard deviation of $\mu_{\mathrm{H}^{+}}$in Table $1\left(0.5 \mathrm{~S} \mathrm{~m}^{-1} \mathrm{M}^{-1}\right)$. In meteoric polar ice, $\mathrm{H}_{2} \mathrm{SO}_{4}$ is often concentrated at grain boundaries [Mulvaney et al., 1988; Barnes and Wolff, 2004] where only a single $\mathrm{H}^{+}$ ion is dissociated from $\mathrm{H}_{2} \mathrm{SO}_{4}$ [Wolff and Paren, 1984; Moore and Fujita, 1993; Fukazawa et al., 1998]. Hence its molar conductivity is similar to $\mathrm{HCl}$ and $\mathrm{HNO}_{3}$, which are the other major acids in polar ice. Here we assign the same molar conductivity to all acid species.

\section{Impurity Concentrations From Major-Ion Chemistry}

[23] Soluble major-ion concentrations are usually measured in meltwater samples taken from ice cores using ion chromatography. $\left[\mathrm{H}^{+}\right]$cannot be directly measured by ion chromatography but it can be estimated using the charge balance of major ions [e.g., Legrand and Mayewski, 1997]. [ss $\mathrm{Cl}^{-}$] is determined using ion chromatography data to separate $\left[\mathrm{Cl}^{-}\right]$into sea-salt and excess components.

\section{1. [ss $\left.\mathrm{Cl}^{-}\right]$}

[24] The total concentration of each ion [X] can be separated into a sum of its sea-salt ([ss X]) and excess, non-sea-salt ([xs X]) components,

$$
[\mathrm{X}]=[\mathrm{ss} \mathrm{X}]+[\mathrm{xs} \mathrm{X}]
$$

It is convenient to represent $[\mathrm{ss} X]$ relative to a reference marine ion and a coefficient $F_{\mathrm{X}}$,

$$
F_{\mathrm{X}}=\frac{[\mathrm{ss} \mathrm{X}]}{\left[\mathrm{ss} \mathrm{Na}^{+}\right]},
$$

where $F_{\mathrm{X}}$ is the ratio of the molalities of $\mathrm{X}$ to $\mathrm{Na}^{+}$in seawater, which are given by Holland [1978]. The molality ratios of $\mathrm{X}$ to any single ion could be used, but $\mathrm{Na}^{+}$is the preferred reference marine ion [Legrand and Delmas, 1988].

[25] $\left[\mathrm{ss} \mathrm{Na}^{+}\right]$is determined using a conservative ion method similar to that described by Dixon et al. [2004]. The concentration $[\mathrm{X}]$ of each ion in a meltwater sample can be used to estimate $\left[\mathrm{ss} \mathrm{Na}{ }^{+}\right]$by setting $[\mathrm{ss} X]=[\mathrm{X}]$ in (5). [ss $\left.\mathrm{Na}^{+}\right]$for the sample is taken to be the smallest value of $\left[\mathrm{ss} \mathrm{Na}^{+}\right]$calculated in this way:

$$
\left[\mathrm{ss} \mathrm{Na}^{+}\right]=\min \left(\frac{[\mathrm{X}]}{F_{\mathrm{X}}}\right) .
$$

[26] This method ensures nonnegative values for [Xs X]. The combination of (4), (5) and (6) is used to calculate $\left[\mathrm{ss} \mathrm{Cl}^{-}\right],\left[\mathrm{ss} \mathrm{SO}_{4}^{2-}\right]$ and $\left[\mathrm{Xs} \mathrm{SO}_{4}^{2-}\right]$.

[27] The conservative ion method assumes that the values of $F_{\mathrm{X}}$ for seawater are valid for the sea salts deposited on the ice sheet. Recent work has shown that frost flowers are also an important source of sea-salt aerosol in Antarctica [e.g., Rankin et al., 2004]. Compared to seawater, [ $\mathrm{SO}_{4}^{2-}$ ] is depleted by $\sim 67 \%$ in frost flowers and $\left[\mathrm{Na}^{+}\right]$is depleted by $\sim 10 \%$ [Rankin et al., 2000]. Hence $F_{\mathrm{SO}_{4}}$ for sea salt that originated from frost flowers is less than that for seawater; [Xs $\mathrm{SO}_{4}^{2-}$ ] may be underestimated if $F_{\mathrm{SO}_{4}}$ is simply assumed to be the seawater ratio. Although depletion of $\left[\mathrm{Na}^{+}\right]$in frost flowers affects all values of $F_{\mathrm{X}}$, the amount of depletion is small and we do not adjust $F_{\mathrm{X}}$ for possible $\left[\mathrm{Na}^{+}\right]$depletion.

[28] For the top $22 \mathrm{~m}$ of the 1994 Siple Dome core, Rankin et al. [2004] estimated that at least $43 \%$ of the total sea salt input in the past $\sim 100$ a at Siple Dome came from frost flowers. Here we assume that this ratio of frost flower to sea-spray salt is valid for the entire ice thickness and treat $F_{\mathrm{SO}_{4}}$ as $(0.43(1-0.67))+(1-0.43)=71 \%$ of its seawater value for the entire Siple Dome record. The overall effect on $\left[\mathrm{H}^{+}\right]$is small (section 3.2): accounting for the effect of frost flowers decreases the mean estimate of $\left[\mathrm{H}^{+}\right]$by less than $0.06 \mu \mathrm{M}$.

\section{2. $\left[\mathrm{H}^{+}\right]$}

[29] The charge balance for melted ice samples using molar concentrations is [Legrand and Mayewski, 1997]

$$
\begin{gathered}
2\left[\mathrm{Ca}^{2+}\right]+\left[\mathrm{H}^{+}\right]+\left[\mathrm{K}^{+}\right]+ \\
2\left[\mathrm{Mg}^{2+}\right]+\left[\mathrm{Na}^{+}\right]+\left[\mathrm{NH}_{4}^{+}\right]
\end{gathered}=\begin{gathered}
{\left[\mathrm{CH}_{3} \mathrm{COO}^{-}\right]+\left[\mathrm{CH}_{3}^{-}\right]+\left[\mathrm{CO}_{3}^{-}\right]+\left[\mathrm{HCOO}^{-}\right]+} \\
{\left[\mathrm{NO}_{3}^{-}\right]+2\left[\mathrm{SO}_{4}^{2-}\right]}
\end{gathered}
$$

[30] The ions present in an ice sheet depend on location. For example, $\left[\mathrm{NH}_{4}^{+}\right]$and several organic acids contribute to the charge balance in Greenland [e.g., Legrand and de Angelis, 1996], but in Antarctica, concentrations of $\left[\mathrm{F}^{-}\right]$ and most of the organic acids except $\left[\mathrm{CH}_{3} \mathrm{SO}_{3}^{-}\right]$are either very low or undetectable [Legrand et al., 1988; Legrand and Mayewski, 1997]. Although $\left[\mathrm{NH}_{4}^{+}\right]$was detected in the earlier shallow Siple Dome core [Mayewski et al., 1995], it was either low or undetectable in subsequent measurements on the main core.

[31] The charge balance in (7) applies to meltwater samples, but in ice, $\mathrm{H}_{2} \mathrm{SO}_{4}$ is only singly dissociated into $\mathrm{H}^{+}$and $\mathrm{HSO}_{4}^{-}$at the grain boundaries (section 2.3.2). To apply the charge balance calculated in meltwater to a charge balance in ice, we separate $\left[\mathrm{SO}_{4}^{2-}\right]$ into its sea-salt and excess contributions using (4). We assume that the crustal contribution to $\left[\mathrm{SO}_{4}^{2-}\right.$ ] is negligible [Castellano et al., 2004] and that all [xs $\left.\mathrm{SO}_{4}^{2-}\right]$ is associated with $\mathrm{H}_{2} \mathrm{SO}_{4}$ 
and thus substitute $2\left[\mathrm{SO}_{4}^{2-}\right]$ measured in meltwater with $2\left[\mathrm{ss} \mathrm{SO}_{4}^{2-}\right]+\left[\mathrm{xs} \mathrm{SO}_{4}^{2-}\right]$.

[32] For application to the Siple Dome ice core, we ignore undetected ions $\left(\left[\mathrm{CH}_{3} \mathrm{COO}^{-}\right],\left[\mathrm{F}^{-}\right],\left[\mathrm{HCOO}^{-}\right],\left[\mathrm{NH}_{4}^{+}\right]\right)$, apply the above substitution for $\left[\mathrm{SO}_{4}^{2-}\right]$ and rearrange (7) to calculate $\left[\mathrm{H}^{+}\right]$,

$$
\begin{aligned}
{\left[\mathrm{H}^{+}\right]=} & {\left[\mathrm{Cl}^{-}\right]+\left[\mathrm{NO}_{3}^{-}\right]+2\left[\mathrm{ss} \mathrm{SO}_{4}^{2-}\right]+\left[\mathrm{xs} \mathrm{SO}_{4}^{2-}\right]+\left[\mathrm{CH}_{3} \mathrm{SO}_{3}^{-}\right] } \\
& -2\left[\mathrm{Ca}^{2+}\right]-\left[\mathrm{K}^{+}\right]-2\left[\mathrm{Mg}^{2+}\right]-\left[\mathrm{Na}^{+}\right] .
\end{aligned}
$$

Because $\left(2\left[\mathrm{ss} \mathrm{SO}_{4}^{2-}\right]+\left[\mathrm{xs}^{\mathrm{SO}}{ }_{4}^{2-}\right]\right)<2\left[\mathrm{SO}_{4}^{2-}\right],\left[\mathrm{H}^{+}\right]$ calculated using (8) can be negative. Negative values of $\left[\mathrm{H}^{+}\right]$, which occurred for less than $6 \%$ of all samples from Siple Dome, are set to zero.

[33] Generally, the sum of the major ions detected by ion chromatography is charge-balanced to within the precision of the measurements. Legrand and de Angelis [1996] compared a calculation of $\left[\mathrm{H}^{+}\right]$using a charge balance to direct measurements of $\left[\mathrm{H}^{+}\right]$using acid titration for ice from Summit, Greenland. They found imbalances equivalent to $2-25 \%$ of the measured $\left[\mathrm{H}^{+}\right]$. Legrand and Delmas [1988] and Moore et al. $[1989,1992 \mathrm{~b}]$ also found good agreement between $\left[\mathrm{H}^{+}\right]$calculated from charge balances and acid titration measurements. We assume that the uncertainty in the charge-balance calculation of $\left[\mathrm{H}^{+}\right]$is $0.5 \mu \mathrm{M}$, which is similar to previously reported differences between $\left[\mathrm{H}^{+}\right]$ calculated using charge balances and acid titration measurements. Because no other independent method exists for measuring $\left[\mathrm{ss} \mathrm{Cl}^{-}\right]$, we assign it the same uncertainty as for $\left[\mathrm{H}^{+}\right]$.

\section{Depth-Averaged Attenuation}

[34] The attenuation length $L_{a}$ is the e-folding length of radar power attenuation and it is inversely proportional to the high-frequency conductivity of ice [e.g., Jackson, 1975],

$$
L_{a}=\frac{\varepsilon_{0} \sqrt{\varepsilon_{r}^{\prime}} c}{\sigma}
$$

where $\varepsilon_{0}$ is the permittivity of free space, $\varepsilon_{r}^{\prime}$ is the real part of the relative permittivity of ice and $c$ is the speed of light in the vacuum.

[35] The $\varepsilon_{r}^{\prime}$ depends on ice temperature, impurity concentrations and frequency, although these dependencies are weaker than those for conductivity. The $\varepsilon_{r}^{\prime}$ of pure ice decreases less than $2 \%$ from $1 \mathrm{MHz}$ to $39 \mathrm{GHz}$ [Matsuoka et al., 1997b] and increases $\sim 1 \%$ from $-80^{\circ} \mathrm{C}$ to $-5^{\circ} \mathrm{C}$ at microwave frequencies [Matsuoka et al., 1997a]. The effect of $\left[\mathrm{H}^{+}\right]$on $\varepsilon_{r}^{\prime}$ is larger at lower frequencies and higher temperatures [Fujita et al., 2000]. Matsuoka et al. [1996] estimated that $\varepsilon_{r}^{\prime}$ at $-10^{\circ} \mathrm{C}$ would increase by $3 \%$ and $2 \%$ at $2 \mathrm{MHz}$ and $10 \mathrm{MHz}$, respectively, for an $\left[\mathrm{H}^{+}\right]$increase of $10 \mu \mathrm{M}$. Overall, for the temperature range -40 to $-10^{\circ} \mathrm{C}$ and the impurity range 0 to $10 \mu \mathrm{M}, \varepsilon_{r}^{\prime}$ is 3.23 at $2 \mathrm{MHz}$ and 3.20 at $10 \mathrm{MHz}$. Here we use $\varepsilon_{r}^{\prime}=3.22$ and assume that it is independent of temperature, impurity concentration and frequency within the range of $0.1-300 \mathrm{MHz}$.
[36] It is often more convenient to describe radar attenuation in an ice sheet in terms of a one-way attenuation rate $N_{a}$,

$$
N_{a}=\frac{1000\left(10 \log _{10} \mathrm{e}\right)}{L_{a}} \approx 0.912 \sigma
$$

where $N_{a}$ is in $\mathrm{dB} \mathrm{km}^{-1}, L_{a}$ is in $\mathrm{m}$ and $\sigma$ is in $\mu \mathrm{S} \mathrm{m} \mathrm{m}^{-1}$ [Winebrenner et al., 2003].

[37] For the frequency range of the traverse data used at Siple Dome (3-5 MHz), the transmitted power into the ice sheet was reduced mainly by attenuation by dielectric absorption and geometric spreading. Appendix A shows that power losses from reflections at internal layers are negligible in this frequency range. Losses from birefringence are also negligible in this frequency range [Fujita et $a l ., 2006]$ and losses from volume scattering are expected to be small in crevasse-free regions since the wavelengths in ice $(35-55 \mathrm{~m})$ of this frequency range are larger than the size of volume scatterers. Hence we ignore power losses from reflections at internal layers, birefringence and volume scattering.

[38] Radar-derived estimates of attenuation give the depth-averaged attenuation to a reflector. To compare our modeled attenuation at Siple Dome with the radar-derived attenuation [Winebrenner et al., 2003], we calculate the depth-averaged modeled attenuation rate $N_{a}^{*}$. The power loss due to attenuation within a depth increment $\Delta z_{i}$ in the ice column is simply $N_{a}\left(\Delta z_{i}\right) \cdot \Delta z_{i}$. The depth-averaged attenuation rate to a reflector at a depth $z$ over $m$ discrete depth increments is

$$
N_{a}^{*}(z)=\frac{1}{z} \sum_{i=1}^{m} N_{a}\left(\Delta z_{i}\right) \cdot \Delta z_{i} .
$$

$\Delta z_{i}$ is determined by the sampling intervals of the measurements of impurity concentrations and temperature, which are treated as constant across $\Delta z_{i}$.

\section{Application to Siple Dome}

\subsection{Borehole and Ice-Core Data}

[39] The temperature profile down the 1004-m borehole was measured using the same system described by Clow et al. [1996]. The basal temperature is $-2.35^{\circ} \mathrm{C}$. Depth intervals of borehole temperature measurements range from 0.093 to $0.102 \mathrm{~m}$ and the mean depth interval is less than $0.10 \mathrm{~m}$. J. Fitzpatrick (personal communication, 2006) provided the measurements of density along the Siple Dome core.

[40] Concentrations of major ions $\left(\left[\mathrm{Ca}^{2+}\right],\left[\mathrm{Cl}^{-}\right],\left[\mathrm{K}^{+}\right]\right.$, $\left.\left[\mathrm{Mg}^{2+}\right],\left[\mathrm{Na}^{+}\right],\left[\mathrm{NO}_{3}^{-}\right],\left[\mathrm{SO}_{4}^{2-}\right]\right)$ were measured using ion chromatography on the upper $974 \mathrm{~m}$ of the ice core. Depth intervals of major-ion samples range from 0.003 to $1.58 \mathrm{~m}$ and the mean depth interval is $0.21 \pm 0.10 \mathrm{~m}$. $\left[\mathrm{CH}_{3} \mathrm{SO}_{3}^{-}\right]$ was measured separately at about the same depth intervals [Saltzman et al., 2006].

[41] Ion chromatography measurements in the depth range 974-1004 $\mathrm{m}$ are not available. Visually, this basal ice appears to be clean and debris-free [Gow and Engelhardt, 

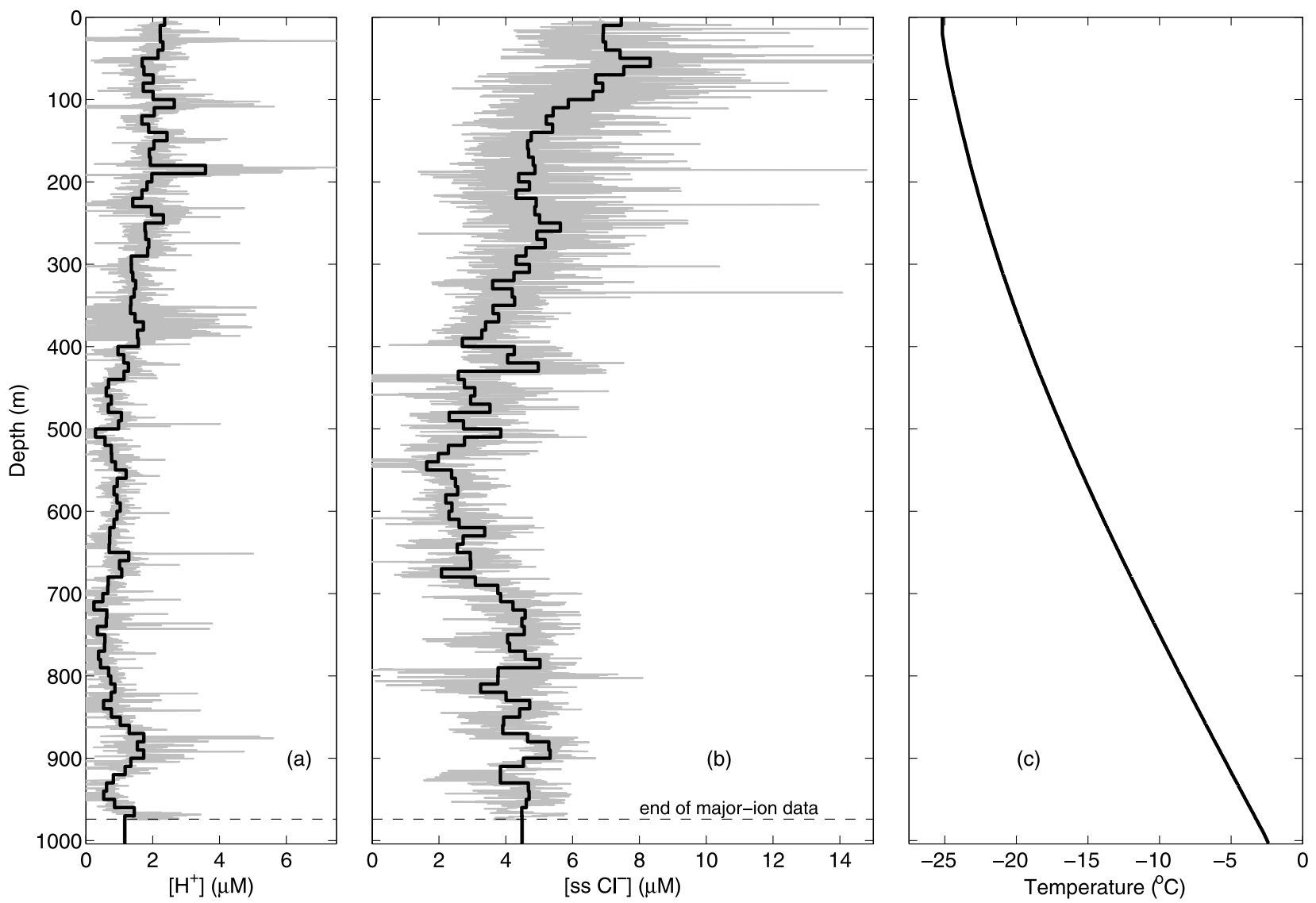

Figure 2. Siple Dome ice-core and borehole data used to model attenuation. (a) $\left[\mathrm{H}^{+}\right]$profile calculated using (8). (b) [ss $\left.\mathrm{Cl}^{-}\right]$profile calculated using (5). For Figures $2 \mathrm{a}$ and $2 \mathrm{~b}$ the concentration axes are at the same scale, the gray lines are the raw profiles, the black lines are the data averaged at $10-\mathrm{m}$ intervals and the horizontal dashed line represents the largest depth for which major-ion data are available $(974 \mathrm{~m})$.

(c) Measured temperature profile.

2000], so we assume that the impurity concentrations in this ice are the same as the mean concentrations in the adjacent $30-\mathrm{m}$ interval $(944-974 \mathrm{~m})$. The mean value of $\left[\mathrm{H}^{+}\right]$for this depth range is $1.1 \mu \mathrm{M}$ and the mean value of [ss $\mathrm{Cl}^{-}$] is $4.5 \mu \mathrm{M}$. While this approximation is not ideal, accurate knowledge of $\left[\mathrm{H}^{+}\right]$and $\left[\mathrm{ss} \mathrm{Cl}^{-}\right]$within this depth range is not too critical because temperatures near $-3^{\circ} \mathrm{C}$ at the bed imply that attenuation there is dominated by the pure ice contribution (Figure 1).

[42] Electrical conductivity measurements (ECM) and CCM measurements were also made along most of the core [e.g., Taylor and Alley, 2004] but these measurements were not calibrated with direct measurements of $\left[\mathrm{H}^{+}\right]$using acid titration. Relationships between these electrical data and our calculated $\left[\mathrm{H}^{+}\right]$and $\left[\mathrm{ss} \mathrm{Cl}^{-}\right]$profiles are discussed in Appendix B.

\subsection{Modeled Attenuation at the Ice-Core Site}

[43] Measurements discussed in section 5.1 were made at varying depth intervals. We spatially average the measurements of temperature, density and impurity concentrations. Figure 2 shows the impurity concentrations and temperature at $10-\mathrm{m}$ intervals. The density profile is not shown, but it is used to correct $\varepsilon_{r}^{\prime}$ in (9) for its density dependence using Looyenga's dielectric mixing equation [Kovacs et al., 1995] and also to correct $\sigma$ in (1) for its density dependence (section 2.1).

[44] The conductivity profile is calculated using (1) and converted into an attenuation rate profile using (10). Figure 3 shows the contributions of the pure ice, $\mathrm{H}^{+}$and ss $\mathrm{Cl}^{-}$components to the attenuation rate profile. As temperature increases with depth, so does the attenuation rate. At temperatures higher than $\sim-23^{\circ} \mathrm{C}$ (depths greater than $\sim 200 \mathrm{~m}$ ), the pure ice component of the attenuation exceeds the $\mathrm{H}^{+}$and $\mathrm{ss} \mathrm{Cl}^{-}$components and begins to dominate the attenuation rate profile. However, even at depths below $\sim 200 \mathrm{~m}$, depth variations in impurity concentrations can still produce changes in the total attenuation rate profile. At the bed, the depth-averaged modeled attenuation rate at the ice-core site is $20.0 \pm 5.7 \mathrm{~dB} \mathrm{~km}^{-1}$. If the $\mathrm{H}^{+}$and $\mathrm{ss} \mathrm{Cl}^{-}$components of the conductivity model are ignored in this calculation, the modeled attenuation rate decreases to $13.7 \pm 5.3 \mathrm{~dB} \mathrm{~km}^{-1}$; this result emphasizes the importance of impurity concentration data for modeling attenuation. 


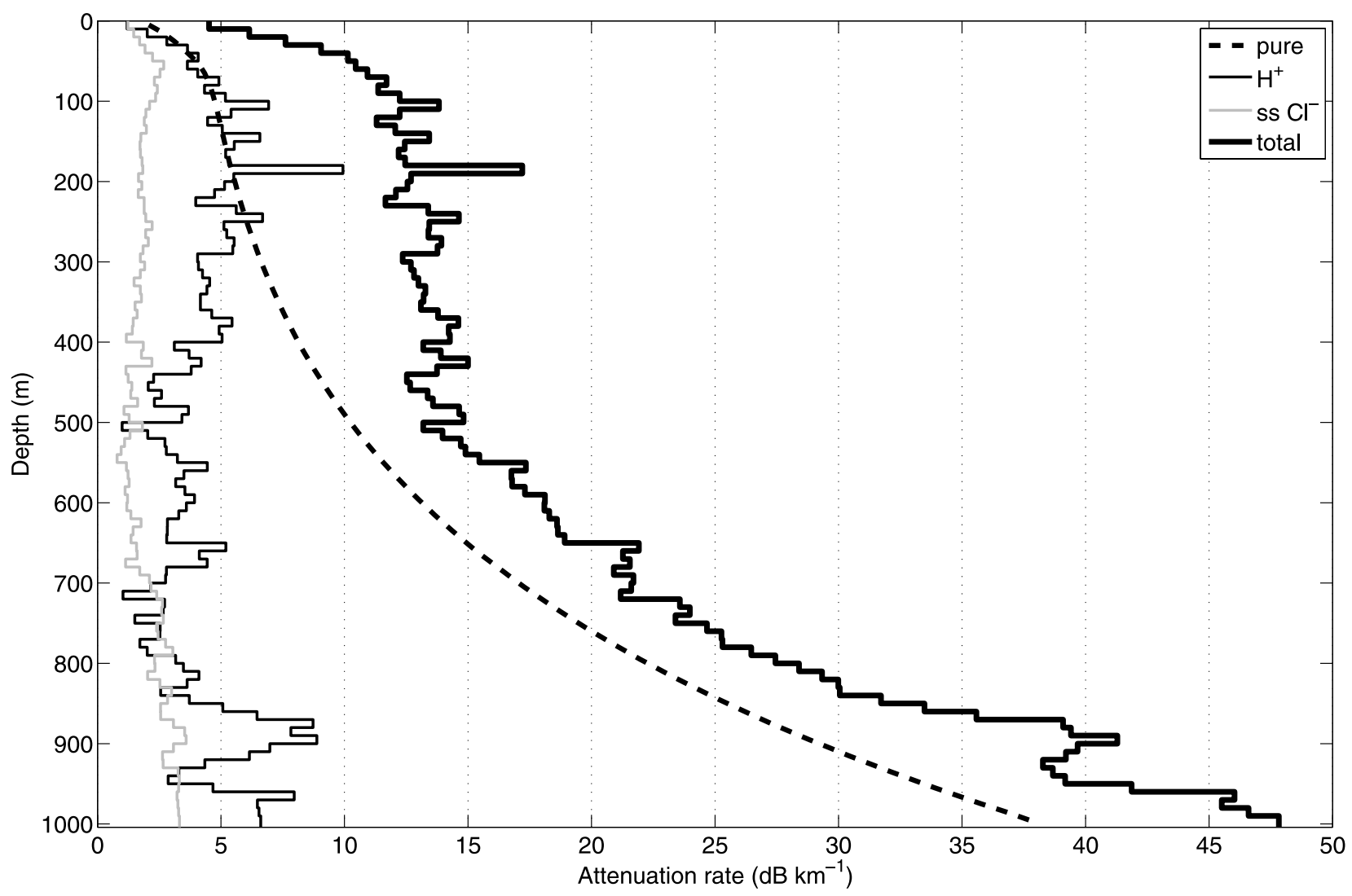

Figure 3. Contribution of pure ice, $\mathrm{H}^{+}$and $\mathrm{ss} \mathrm{Cl}^{-}$components to the modeled attenuation rate profile $\left(N_{a}\right)$ at Siple Dome. At the bed, the depth-averaged modeled attenuation rate $\left(N_{a}^{*}\right)$, calculated from (11), is $20.0 \pm 5.7 \mathrm{~dB} \mathrm{~km}^{-1}$.

[45] Figure 4 shows the depth-averaged modeled attenuation rate profile $\left(N_{a}^{*}\right)$ at Siple Dome. The value of this profile at the bed is the same as the depth-normalized attenuation rate using the entire total attenuation rate profile $\left(N_{a}\right)$ shown in Figure 3. The depth-averaged attenuation rate does not respond quickly to changes in the total attenuation rate because it is an average of the total attenuation rate profile between the surface and any given depth. Hence the depth-averaged attenuation rate profile is not strongly influenced by rapid changes in the contribution of attenuation from impurities, but it is primarily influenced by the temperature profile.

\subsection{Radar-Derived Attenuation}

[46] The depth-averaged modeled attenuation rate can be compared to that derived from radar measurements. Winebrenner et al. [2003] calculated the depth-averaged attenuation rate at Siple Dome using two different methods. Using common midpoint data, where the transmitting and receiving antennae are progressively separated from a fixed midpoint, they examined the relationship between basal echo intensity and the radar path length through the ice and calculated an attenuation rate of $35.0 \mathrm{~dB} \mathrm{~km}^{-1}$ at a location $\sim 4 \mathrm{~km}$ southeast of the ice divide. However, the common midpoint data were not corrected for the angular dependence of the beam pattern, which is important [e.g., Arcone, 1995] but not known for the system used to the make the measurements. Because of this uncertainty, we do not use the attenuation rate derived from the commonmidpoint method.

[47] Using data from a $125 \mathrm{~km}$ traverse across the ice divide, Winebrenner et al. [2003] calculated an attenuation rate of $25.9 \mathrm{~dB} \mathrm{~km}^{-1}$. This required the assumption that the basal reflectivity and the depth-averaged attenuation rate

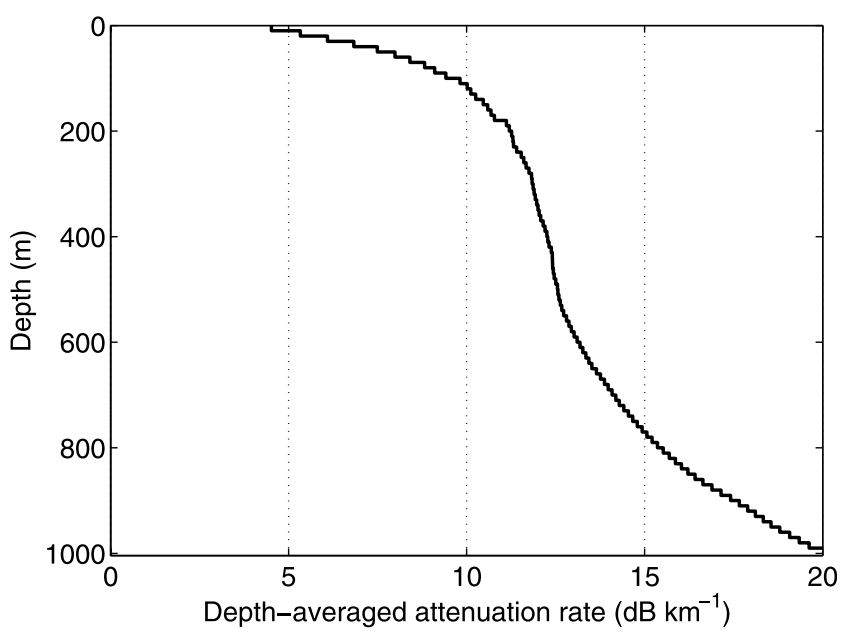

Figure 4. Depth-averaged modeled attenuation rate profile $\left(N_{a}^{*}\right)$ at Siple Dome calculated using (11) at all depths. 
Table 2. Separate Adjustments to the Mean Values of the Dielectric Properties and Impurity Concentrations in Equation (1) That are Necessary to Match the Modeled and Radar-Derived Attenuation at Siple Dome ${ }^{\mathrm{a}}$

\begin{tabular}{lccl}
\hline Parameter & Units & Original Value & $\begin{array}{c}\text { Adjusted Value } \\
\text { (\% Increase) }\end{array}$ \\
\hline$E_{\text {pure }}$ & $\mathrm{eV}$ & 0.55 & $0.71(29 \%)$ \\
$E_{\mathrm{H}+}$ & $\mathrm{eV}$ & 0.20 & $0.72(260 \%)$ \\
$E_{\mathrm{ss} \mathrm{Cl}}$ & $\mathrm{eV}$ & 0.19 & $0.87(358 \%)$ \\
$\sigma_{\text {pure }}$ & $\mu \mathrm{S} \mathrm{m}^{-1}$ & 6.6 & $9.1(38 \%)$ \\
$\mu_{\mathrm{H}+}$ & $\mathrm{S} \mathrm{m}^{-1} \mathrm{M}^{-1}$ & 3.2 & $7.2(125 \%)$ \\
$\mu_{\mathrm{ss} \mathrm{Cl}^{-}}$ & $\mathrm{S} \mathrm{m}^{-1} \mathrm{M}^{-1}$ & 0.43 & $1.56(263 \%)$ \\
{$\left[\mathrm{H}^{+}\right]$} & $\mu \mathrm{M}$ & 1.3 & $2.7(108 \%)$ \\
{$\left[\mathrm{ss} \mathrm{Cl}^{-}\right]$} & $\mu \mathrm{M}$ & 4.2 & $15.0(257 \%)$ \\
\hline
\end{tabular}

${ }^{a}$ Each original value is adjusted separately while the other dielectric properties and impurity concentrations are kept at their original values. The original mean impurity concentrations shown here are for the $10-\mathrm{m}$ averaged data. Also, these adjustments are implemented at all temperatures rather than a specific temperature range, which is considered for $E_{\mathrm{H}^{+}}$in section 6.2.3.

were constant across the traverse. We suspect that those assumptions are not valid far to the north of the ice divide. Beyond $54 \mathrm{~km}$ north, the radar traverse crosses into the relict Siple Ice Stream, where the bed reflection powers (BRPs) are much higher, indicating a different basal condition than that under most of Siple Dome [Gades et al., 2000]. Here we restrict the attenuation calculation to data within $54 \mathrm{~km}$ both north and south of the ice divide. We have made several adjustments to the traverse method presented by Winebrenner et al. [2003], which are explained in Appendix C. The updated radar-derived depth-averaged attenuation rate is $25.3 \pm 1.1 \mathrm{~dB} \mathrm{~km}^{-1}$.

[48] Radar-derived attenuation rates to several reflectors could constrain the depth-averaged attenuation rate profile and provide additional tests for the attenuation model. However, the calculation of attenuation rates using internal reflections requires bright, isolated reflectors, which are uncommon at radar frequencies less than $10 \mathrm{MHz}$ [e.g., Jacobel and Welch, 2005]. Here we only use the basal reflector because we could not calculate reliable attenuation rates using internal reflections at Siple Dome.

\section{Discussion}

[49] In section 5.2, we presented the modeled depthaveraged attenuation rate at Siple Dome using our standard conductivity model from Table 1 . In sections 6.1 and 6.2, we consider adjustments to the conductivity model that may explain the difference between the modeled and radarderived attenuation rates.

\subsection{Matching Modeled and Radar-Derived Attenuation}

[50] Here we assume that the radar-derived attenuation rate at Siple Dome is correct and adjust each dielectric property and impurity concentration in (1) to match the modeled and radar-derived attenuation rates. Each adjustment is made separately while keeping the other dielectric properties and impurity concentrations at their original values; these results are shown in Table 2. For $\left[\mathrm{H}^{+}\right]$, [ss $\mathrm{Cl}^{-}$] and the dielectric properties associated with these impurities, large adjustments relative to their original values are necessary to match the modeled and radar-derived values; smaller relative adjustments are needed for the pure ice dielectric properties.

[51] For the englacial temperatures present at Siple Dome, the dominance of the pure ice contribution to attenuation (Figure 3 ) is consistent with the higher sensitivity of the depth-averaged modeled attenuation rate to the pure ice dielectric properties (Figure 1). The adjusted value for $\sigma_{\text {pure }}$ is within its reported range (Table 1) and is the smallest adjustment relative to the original value, whereas the adjusted values for all other dielectric properties are outside of their respective reported ranges and are large adjustments relative to their original values. We therefore prefer to only adjust $\sigma_{\text {pure }}$ to calibrate the conductivity model using the radar-derived attenuation rate at Siple Dome and conclude that uncertainty in $\sigma_{\text {pure }}$ is the most problematic component of our modeling. More precise measurements of the $\sigma_{\text {pure }}$ over a wide temperature range, including the temperatures close to the melting point, are crucial.

[52] Alternatively, we can adjust values of the dielectric properties to those from preferred sources. Using only the values of $\sigma_{\text {pure }}$ and $E_{\text {pure }}$ derived from Johari and Charette [1975] (Table 1) and keeping the other dielectric properties at their original values yields a depth-averaged modeled attenuation rate of $24.0 \pm 2.2 \mathrm{~dB} \mathrm{~km}^{-1}$ at Siple Dome, which is in good agreement with the radar-derived attenuation rate. Their experiments included a relatively large number of measurements of the conductivity of pure ice that also covered the range of temperatures present at Siple Dome, including temperatures near the melting point.

\subsection{Unmodeled Physics}

\subsubsection{Melting-Point Depression}

[53] Most of the conductivity experiments referenced in Table 1 were performed at atmospheric pressure. However, the melting point of ice is depressed by pressure and soluble impurities [Paterson, 1994]. This temperature depression is expected to increase the mobility of impurities in the ice, effectively increasing the ice conductivity [Wolff and Paren, 1984]. Ignoring the firn, the melting point depression for ice overburden is $-8.7 \times 10^{-4} \mathrm{~K} \mathrm{~m}^{-1}$. However, Johari and Charette [1975] measured conductivity at a range of hydrostatic pressures $\left(10^{5}-10^{7} \mathrm{~Pa}\right)$ and did not observe any change in conductivity. The adjustment for sea-ice salinity is $-2.03 \mathrm{~K} \mathrm{M}^{-1}$ and this adjustment is also inversely proportional to the fractional water content in the ice [Paterson, 1994]. The salinities present in meteoric polar ice are generally less than $15 \mu \mathrm{M}$ (e.g., Figure $2 \mathrm{~b}$ ), so the correction for salinity is less than $-0.001 \mathrm{~K}$ and is ignored in this study. Assuming that the melting-point depression due to acids is similar to that of salinity, we also do not correct for acids. To examine the possible importance of the pressure-melting effect, we adjust the measured temperature profile by adding the pressure-melting correction due to the ice overburden and calculate an adjusted attenuation rate that is $0.9 \mathrm{~dB} \mathrm{~km}^{-1}$ larger than our original modeled value. This value is closer to the radar-derived value.

\subsubsection{Eutectic Point of $\mathrm{NaCl}$}

[54] Matsuoka et al. [1997a] found that the molar conductivity of $\mathrm{NaCl}$-doped ice at $5 \mathrm{GHz}$ decreased by more than $50 \%$ across the eutectic point of $\mathrm{NaCl}\left(-21^{\circ} \mathrm{C}\right)$ 
and that $\mathrm{NaCl}$ existed primarily in the liquid phase in their samples. However, the $\mathrm{Cl}^{-}$ions that contribute to the conductivity of meteoric ice are believed to form defects in the lattice (section 2.1) rather than exist in the liquid phase. Furthermore, Moore et al. [1992a] did not observe this phenomenon while using DEP $(300 \mathrm{kHz})$ on ice core samples with large values of $\left[\mathrm{ss} \mathrm{Cl}^{-}\right]$across a range of temperatures that crossed the eutectic point of $\mathrm{NaCl}$ [Moore et al. [1992a, Figure 4]. Conductivity due to [ss $\left.\mathrm{Cl}^{-}\right]$is probably dispersive [Moore and Fujita, 1993], so a change in conductivity across the eutectic point of $\mathrm{NaCl}$ may not be apparent at or below $300 \mathrm{kHz}$. The eutectic temperature of $\mathrm{NaCl}$ occurs at a depth of $\sim 310 \mathrm{~m}$ at Siple Dome, so it is possible that the ss $\mathrm{Cl}^{-}$component of conductivity changes abruptly there if $\mathrm{NaCl}$ is present in the liquid phase. To examine the possible importance of this effect, we simply assume that $\left[\mathrm{ss} \mathrm{Cl}^{-}\right]$does not contribute to conductivity at temperatures below its eutectic point. This yields an attenuation rate that is $0.6 \mathrm{~dB} \mathrm{~km}^{-1}$ smaller than our original modeled value and differs further from the radar-derived value.

[55] Matsuoka et al. [1997a] also found that the molar conductivity of acid-doped ice decreased significantly below the eutectic point of two acid species, $\mathrm{HNO}_{3}$ $\left(-43^{\circ} \mathrm{C}\right)$ and $\mathrm{H}_{2} \mathrm{SO}_{4}\left(-73^{\circ} \mathrm{C}\right)$, which are believed to be in the liquid phase in meteoric ice. Fujita et al. [2002] observed a decrease in the apparent activation energy of the AC-ECM conductivity of several Antarctic ice-core samples below $\sim-81^{\circ} \mathrm{C}$. They interpreted this change as due to a large decrease in liquid-phase conduction across the eutectic point of the samples, which had $\left[\mathrm{SO}_{4}^{2-}\right]>8 \mu \mathrm{M}$ and other impurities. However, the eutectic points of $\mathrm{HNO}_{3}$ and $\mathrm{H}_{2} \mathrm{SO}_{4}$ are outside the range of temperatures measured at Siple Dome (Figure 2c) so we do not consider an adjustment to the conductivity model below these temperatures.

\subsubsection{Premelting Ice}

[56] There is some evidence that the dielectric properties of acid-doped ice change when the temperature exceeds about $-10^{\circ} \mathrm{C}$ [Matsuoka et al., 1997a, Figure 2], although this phenomenon is not always observed [e.g., Moore et al., 1992a, Figure 4]. This phenomenon is likely related to melting-point depression (section 6.2.1) and possible explanations include: the surface conductance at grain boundaries may increase as the thickness of the liquid-like layer increases in premelting ice [Petrenko and Whitworth, 1999]; the presence of impurities can also increase the rate of premelting [Wettlaufer, 1999]; $\mathrm{HSO}_{4}^{-}$at grain boundaries dissociates into $\mathrm{H}^{+}$and $\mathrm{SO}_{4}^{2-}$ as the liquid-like layer grows at high temperatures, thus increasing $\left[\mathrm{H}^{+}\right]$. Analogously, the temperature dependence of the mechanical properties of ice change as grain-boundary sliding increases above $-10^{\circ} \mathrm{C}$ [Paterson, 1994]. At Siple Dome, temperatures above $-10^{\circ} \mathrm{C}$ occur at depths below $\sim 750 \mathrm{~m}$, which is about a quarter of the ice thickness, so this phenomenon may be important and present there.

[57] We examine the possible importance of the increased conductivity of premelting ice by arbitrarily doubling the mean value of $E_{\mathrm{H}^{+}}$to $0.40 \pm 0.08 \mathrm{eV}$ at temperatures above $-10^{\circ} \mathrm{C}$ [Matsuoka et al., 1997a, Figure 2]. In this temperature range, there are few experimental data to constrain dielectric properties and the pure ice contribution dominates conductivity (Figure 1), but $\mathrm{H}^{+}$is the dominant impurity in terms of its contribution to attenuation at Siple Dome (Figure 3). To avoid an unrealistic and unobserved discontinuity in $\mu_{\mathrm{H}+}$ at $-10^{\circ} \mathrm{C}, \mu_{\mathrm{H}+}$ above $-10^{\circ} \mathrm{C}$ is adjusted so that $\mu_{\mathrm{H}+}$ using the original $E_{\mathrm{H}+}$ value is equal to $\mu_{\mathrm{H}+}$ using the doubled $E_{\mathrm{H}+}$ value at $-10^{\circ} \mathrm{C}$. This adjustment yields an attenuation rate that is just $0.2 \mathrm{~dB} \mathrm{~km}^{-1}$ larger than our original modeled value.

\subsection{Influence of Spatial Variability on Radar-Derived Attenuation}

[58] Spatial variations in impurity and temperature profiles complicate interpretation of the radar-derived attenuation from traverse data. The traverse data used in section 5.3 sampled ice from points up to $54 \mathrm{~km}$ away from the ice core. However, cold ice is advected downward from the ice divide toward the flanks, so the flanks are presumably colder than the ice divide. Also, the rheology of ice at low deviatoric stresses causes higher temperatures that are localized underneath the ice divide [e.g., Nereson and Waddington, 2002]. Ice thickness and accumulation rate gradients [Nereson et al., 2000] will also produce asymmetry in the englacial temperatures across Siple Dome. The attenuation rate at the Siple Dome ice divide therefore may be larger than the value derived from traverse data, which also sampled ice at lower temperatures on the flanks.

[59] Restricting the traverse data to within $5 \mathrm{~km}$ of the ice divide and recalculating the attenuation rate, this gives an unreasonably high attenuation rate $\left(66 \mathrm{~dB} \mathrm{~km}^{-1}\right)$ with a large uncertainty $\left(>30 \mathrm{~dB} \mathrm{~km}^{-1}\right)$, which is not supported by direct observations of the BRPs over this portion of the traverse. This result also implies that caution is needed when estimating attenuation from such restricted traverse data. To calculate the attenuation rate using traverse data requires BRPs from a range of ice thicknesses comparable to or greater than the attenuation length. This condition is satisfied for the traverse data at Siple Dome used to calculate the radar-derived attenuation rate (section 5.3), where the range of ice thicknesses $(\sim 350 \mathrm{~m})$ is approximately double the radar-derived attenuation length $(172 \mathrm{~m})$.

\subsection{Comparison to Attenuation at Other Sites}

[60] The modeled and radar-derived estimates of the depth-averaged attenuation rate at Siple Dome are not directly applicable to other sites. Different locations and glaciological settings have different impurity and temperature profiles, which control the attenuation rate profile. However, it is helpful to compare the modeled and radarderived attenuation at Siple Dome to other sites and place it in the context of previous estimates of attenuation in ice sheets.

[61] Bentley et al. [1998] calculated an attenuation rate of $17.3 \mathrm{~dB} \mathrm{~km}^{-1}$ for the Ross Ice Shelf at the outlet of Kamb Ice Stream, which is $\sim 100 \mathrm{~km}$ from Siple Dome, by assuming that the reflections underneath their survey region were from seawater. Using the same method, Peters et al. [2005] calculated an attenuation rate of $18 \mathrm{~dB} \mathrm{~km}^{-1}$ for Kamb Ice Stream. Both Bentley et al. [1998] and Peters et al. [2005] derived basal reflectivity maps of their study regions that are consistent with glaciological expectations. Their attenuation rates on or near Kamb Ice Stream are lower than the modeled and radar-derived values at Siple Dome. This difference in attenuation rates may be consis- 
tent with differences in observed temperature profiles: measured profiles from further upstream on Kamb Ice Stream all show higher basal temperature gradients and lower temperatures at intermediate depths than those at Siple Dome [Engelhardt, 2004]. Temperature is the dominant control on ice-sheet attenuation (Figure 3), so regions that have generally higher englacial temperatures will have higher attenuation rates, assuming their mean impurity concentrations are the same.

[62] Separately, Peters et al. [2005] calculated an attenuation rate of $21 \mathrm{~dB} \mathrm{~km}^{-1}$ at Whillans Ice Stream using the temperature-attenuation relationship of Gudmandsen [1971] and a measured borehole temperature profile. Combining the temperature-attenuation relationship of Gudmandsen [1971] and the measured temperature profile at Siple Dome (Figure 2c) yields an attenuation rate of $21.5 \mathrm{~dB} \mathrm{~km}^{-1}$. This value is near the modeled and radar-derived values for Siple Dome, but the agreement is coincidental. Impurity concentrations were implicitly included in the temperature-attenuation relationship of Gudmandsen [1971] (section 2.2.1), but that relationship does not allow for varying impurity concentrations, which can significantly alter attenuation rates (Figure 3). As temperature increases, increases in $\left[\mathrm{H}^{+}\right]$or $\left[\mathrm{ss} \mathrm{Cl}^{-}\right]$produce larger attenuation rate increases compared to equivalent $\left[\mathrm{H}^{+}\right]$or $\left[\mathrm{ss} \mathrm{Cl}^{-}\right]$increases at lower temperatures (Figures 2 and 3).

[63] Corr et al. [1993] estimated attenuation from radar measurements on the Ronne and George VI ice shelves in West Antarctica. We convert their reported attenuation values to attenuation rates: $9 \pm 1 \mathrm{~dB} \mathrm{~km}^{-1}$ at their Ronne Ice Shelf site and $27 \pm 3 \mathrm{~dB} \mathrm{~km}^{-1}$ at their George VI Ice Shelf site. They attributed the difference in attenuation at the two sites to differing mean impurity concentrations. Their ice-shelf sites are more dynamic and proximal to the sea than Siple Dome, especially the George VI site; these sites illustrate the potentially large variability of attenuation rates over spatial scales of $\sim 500 \mathrm{~km}$ and their dependence on relative coastal proximity.

\section{Conclusions}

[64] We have presented a framework for modeling englacial radar attenuation using impurity concentration and temperature profiles from ice cores and boreholes, respectively. The conductivity model used in this study is based on a synthesis of available experimental data. However, the value of $\sigma_{\text {pure }}$ is not well constrained and its uncertainty contributes more than $50 \%$ of the uncertainty in the depthaveraged modeled attenuation rate at Siple Dome. More measurements are needed to reduce the uncertainty in the value of $\sigma_{\text {pure }}$. More measurements are also needed to further quantify the effects of (1) varying firn densities, (2) high pressures to simulate the effect of the pressure overburden in ice sheets and (3) temperatures near the eutectic point of $\mathrm{NaCl}$ and near the melting point.

[65] The depth-averaged modeled attenuation rate at Siple Dome $\left(20.0 \pm 5.7 \mathrm{~dB} \mathrm{~km}^{-1}\right)$ is somewhat lower than the radar-derived value $\left(25.3 \pm 1.1 \mathrm{~dB} \mathrm{~km}^{-1}\right)$. However, an adjustment to $\sigma_{\text {pure }}$ that is within its range of reported values is sufficient to match the modeled and radar-derived attenuation rates. Using the values of $\sigma_{\text {pure }}$ and $E_{\text {pure }}$ derived from Johari and Charette [1975], the modeled attenuation rate is $24.0 \pm 2.2 \mathrm{~dB} \mathrm{~km}^{-1}$, which also matches the radarderived attenuation rate within the uncertainties of these two values. When integrated over a two-way raypath through an ice sheet, the modeled one-way attenuation rate uncertainty $\left(5.7 \mathrm{~dB} \mathrm{~km}^{-1}\right)$ is potentially large compared to the reflectivity difference between wet and dry grounded ice-sheet beds ( 4-26 dB [Peters et al., 2005]), which depends on the dielectric properties of the subglacial interface. This comparison emphasizes the importance of constraining attenuation rate uncertainties for the accurate interpretation of basal echo intensities.

[66] This work shows that impurity concentrations and temperature profiles are needed to model englacial radar attenuation; neglecting the $\mathrm{H}^{+}$and $\mathrm{ss}^{-}$contributions to attenuation decreases the modeled attenuation rate at Siple Dome by more than $30 \%$. Also, variations in impurity concentration profiles, particularly $\left[\mathrm{H}^{+}\right]$, can produce large changes in the attenuation rate profile.

[67] The depth-averaged attenuation rate increases with depth and is primarily controlled by the temperature profile. Radar-derived depth-averaged attenuation rates to internal reflections could thus provide further constraints on the temperature profile. The conductivity model presented here could also be used to study spatial variations in attenuation. Ice-flow models can be used to track englacial temperatures and the vertical strain history along a flowline that passes through an ice-core site [e.g., Nereson and Waddington, 2002; Clarke et al., 2005]. Those model outputs could be used to extrapolate impurity concentration profiles from an ice core on the basis of the vertical strain history and then calculate the spatial variation of attenuation along the flowline.

\section{Appendix A: Reflection Loss}

[68] Power loss at internal reflecting layers could result in an overestimate of attenuation due to dielectric absorption measured by radar. In the frequency range of $1-10 \mathrm{MHz}$, internal reflections are mainly caused by changes in conductivity due to volcanogenic acids [Fujita and Mae, 1994]. The reflectivity $|R|$ for an internal reflection due to an acid layer is calculated following Paren [1981] as $|R|=\left(\Delta \sigma / 8 \pi f \varepsilon_{r}^{\prime} \varepsilon_{0}\right)^{2}$, where $f$ is frequency. The two-way reflection loss $R_{L}$ across $n$ reflectors that have the same $|R|$ is $R_{L}=1-(1-|R|)^{2 n}$. We estimate an upper bound on the magnitude of two-way reflection loss expected in West Antarctica using data from the Byrd ice core, our conductivity model and the above method for calculating layer reflectivities. We use the Byrd ice core to estimate reflection loss rather than the Siple Dome ice core because we prefer to estimate $|R|$ for a ice-core volcanic signal that is clearly matched to a prominent radar layer.

[69] Hammer et al. [1997] reported on volcanism at Byrd detected by ECM and found 57 large volcanic events over the last $\sim 50 \mathrm{ka}$ over a depth range of $88-2164 \mathrm{~m}$. The largest event that they reported occurred $\sim 17.5 \mathrm{ka}$ ago and consists of several $\left[\mathrm{H}^{+}\right]$peaks of $\sim 10 \mu \mathrm{M}$ above a background $\left[\mathrm{H}^{+}\right]$of $1.5 \mu \mathrm{M}$ and a background $\left[\mathrm{ss} \mathrm{Cl}^{-}\right]$of $2.0 \mu \mathrm{M}$. This event corresponds to a prominent radar layer that has been tracked over a large portion of West Antarctica [Jacobel and Welch, 2005]. Using these peak and back- 


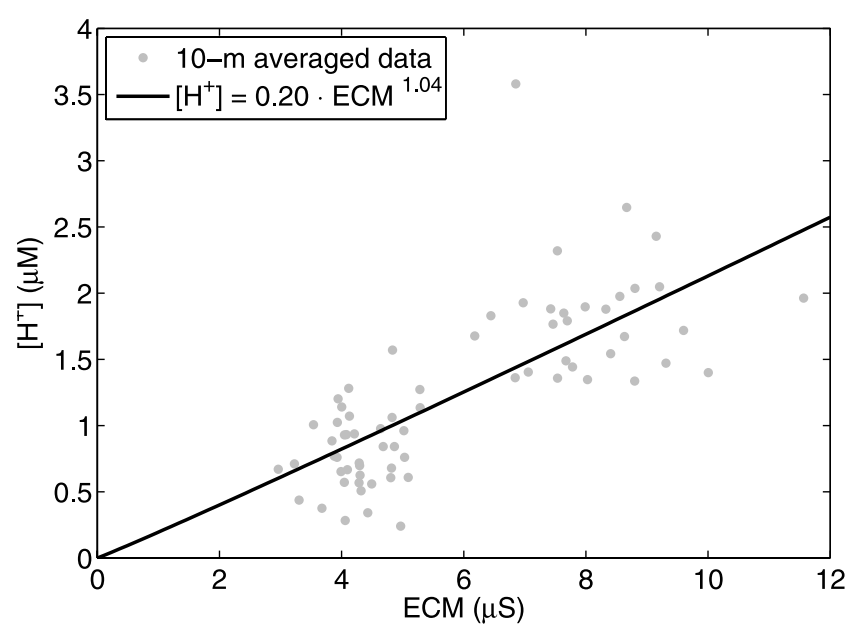

Figure B1. Nonlinear least-squares fit between 10-m averaged ECM and calculated $\left[\mathrm{H}^{+}\right]$profiles within the depth range 100-799 $\mathrm{m}$ at Siple Dome. The fraction of explained variance is 0.56 .

ground concentrations and the measured ice temperature at the depth of this event $\left(-25^{\circ} \mathrm{C}\right.$ [Gow et al., 1968]), we use (1) to calculate the conductivity difference between the acid peaks and the background as $\Delta \sigma=24 \pm 7 \mu \mathrm{S} \mathrm{m} \mathrm{m}^{-1}$. Using $f=1 \mathrm{MHz}$ yields $|R|=-29 \pm 2 \mathrm{~dB}$. This value of $|R|$ is larger than the range of typical values $(-55$ to $-80 \mathrm{~dB})$ reported by Fujita and Mae [1994], so we consider it an end-member case that provides an upper bound on the magnitude of reflection loss at a single layer. The twoway reflection loss after 57 such events, spanning $50 \mathrm{ka}$, is $R_{L}=-0.6 \mathrm{~dB}$ of the power transmitted into the ice sheet. This value of $R_{L}$ is probably a slight underestimate for the last $50 \mathrm{ka}$ because the depth range of $300-900 \mathrm{~m}$ in the Byrd core was not measured by ECM. Multiple reflections between layers are also ignored because Miners et al. [2002] showed that they are small compared to primary reflections.

[70] At Siple Dome, ice from $50 \mathrm{ka}$ ago occurs at a depth of $\sim 900 \mathrm{~m}$ [Brook et al., 2005]. Assuming that the frequency of volcanic events recorded at Siple Dome is similar to that at Byrd, we expect the total two-way reflection loss over the upper $900 \mathrm{~m}$ to be $\sim-0.6 \mathrm{~dB}$. Reflection loss in the lower $\sim 100 \mathrm{~m}$ of the ice will increase this value slightly, but this calculation shows that power loss from internal reflections is small compared to loss from dielectric absorption. The frequency of volcanic events recorded in ice cores is generally higher in Greenland than in Antarctica, so this loss calculation may be an underestimate in Greenland.

\section{Appendix B: Relationships Between Electrical Data and Impurity Concentrations}

[71] Electrical logs of ice cores are often related to impurity concentrations and can be used to independently validate impurity concentration profiles from major-ion data. ECM currents are often found to have a power-law relationship with $\left[\mathrm{H}^{+}\right]$of the form $\left[\mathrm{H}^{+}\right]=a \cdot \mathrm{ECM}^{b}$, where $a$ and $b$ vary depending on the ECM instrument used and the ice cores measured [Wolff et al., 1997]. Direct comparison between raw ECM measurements and calculated $\left[\mathrm{H}^{+}\right]$ profiles is difficult because they were measured at different sampling intervals and have independent noise sources. An independent validation of the $\left[\mathrm{ss} \mathrm{Cl}^{-}\right]$profile using ECM data is not possible because ECM does not respond to the Bjerrum-L defects formed by ss $\mathrm{Cl}^{-}$ions [Wolff et al., 1997].

[72] Here we compare ECM and $\left[\mathrm{H}^{+}\right]$profiles that have been spatially averaged. We only use measurements within the depth range 100-799 $\mathrm{m}$; above $100 \mathrm{~m}$, the ECM currents are lower, probably owing to lower densities in the firn, and ECM was not measured at depths greater than $799 \mathrm{~m}$. Figure B1 shows the nonlinear least-squares fit between these $10-\mathrm{m}$ averaged ECM and $\left[\mathrm{H}^{+}\right]$profiles; the best-fit exponent $(b=1.04 \pm 0.25)$ is lower than the $\left[\mathrm{H}^{+}\right]$ calibrations for most ECM instruments but it does fall within the range of reported values [e.g., Moore et al., $1992 \mathrm{~b}]$. No previous $\left[\mathrm{H}^{+}\right]$calibration exists for the ECM instrument used on the Siple Dome core, so it is not possible to directly compare these best-fit coefficients to previous results. The scatter in this relationship is similar to that for other ice cores [Moore et al., 1992b; Wolff et al., 1995] and the fraction of explained variance is 0.56 ; the fraction of explained variance decreases to 0.42 when averaging over 2-m intervals. Overall, the observed relationship between the ECM and calculated $\left[\mathrm{H}^{+}\right]$profiles is indicative of the validity of (8).

[73] Another electrical method that was used to study the Siple Dome ice core is CCM, which is similar to AC-ECM [e.g., Sugiyama et al., 2000] so we might expect a linear relationship between $\mathrm{CCM}$ and impurity concentrations. However, the Siple Dome CCM data are not calibrated and are reported as conductances, not conductivities. Here we compare CCM data over the same depth range as before $(100-799 \mathrm{~m})$ to the $\left[\mathrm{H}^{+}\right]$and $\left[\mathrm{ss} \mathrm{Cl}^{-}\right]$profiles using a multiple linear regression of the form $\mathrm{CCM}=j+k\left[\mathrm{H}^{+}\right]+$ $l\left[\mathrm{ss} \mathrm{Cl}^{-}\right]$. This yields a value of $k$ that is 3 times larger than $l$, which is lower than the ratio of $\mu_{\mathrm{H}+}$ to $\mu_{\mathrm{ss} \mathrm{Cl}^{-}}$expected from Table 1 (7.4). The fraction of explained variance for this regression using observations averaged over $10-\mathrm{m}$ intervals is 0.55 .

\section{Appendix C: Radar-Derived Attenuation}

[74] Our adjustments to the calculation of attenuation derived from radar traverse data originally presented by Winebrenner et al. [2003] include:

[75] 1. Ice thicknesses are used instead of two-way traveltimes in the attenuation calculation. The radio-wave velocity profile is calculated using the measured density profile with Looyenga's dielectric mixing equation [Kovacs et al., 1995] and is also adjusted for the refraction of the raypath in the firn [e.g., Rasmussen, 1986].

[76] 2. BRPs are calculated using the sinusoidal integration method of Gades et al. [2000]. This produces a more stable estimate of the reflected power than the method used by Winebrenner et al. [2003].

[77] Winebrenner et al. [2003] binned traveltime ranges and used a limited number of BRPs from each bin to avoid 


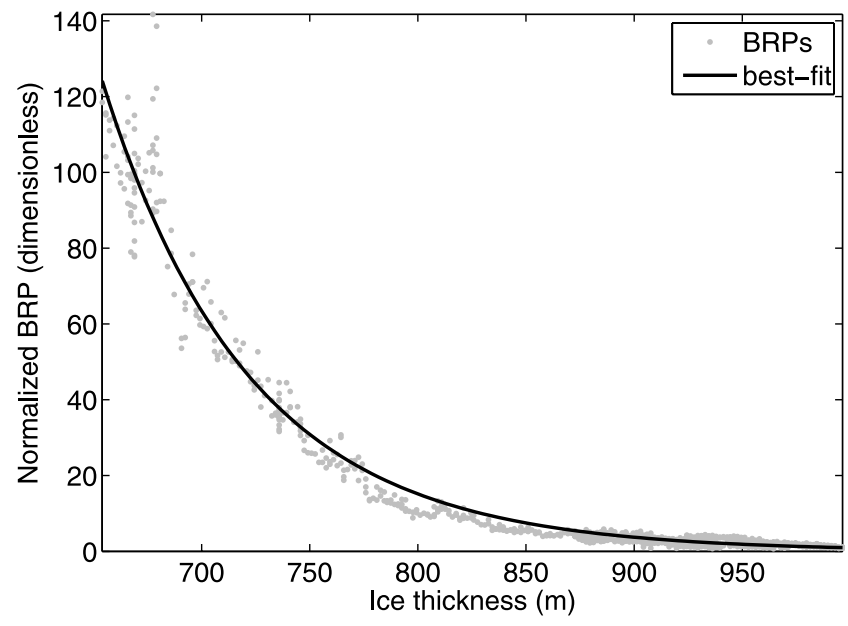

Figure C1. Normalized Siple Dome BRPs from traverse data versus ice thickness. Normalized BRP is calculated as the left-hand side of $(\mathrm{C} 1)$. The solid line is the nonlinear least-squares fit to these data. The traverse data span $54 \mathrm{~km}$ both north and south of the ice divide. The best-fit depthaveraged attenuation rate is $25.3 \pm 1.1 \mathrm{~dB} \mathrm{~km}^{-1}$; the fraction of explained variance is 0.97 .

biasing the fit. However, we find that this binning procedure does not significantly alter the fit. Here we do not bin the data and all BRPs within $54 \mathrm{~km}$ of the ice divide are used.

[78] Winebrenner et al. [2003] used a nonlinear leastsquares relationship that included a calibration for geometric spreading. We eliminate the need to calibrate for geometric spreading by normalizing the $\mathrm{BRPs}$ by $\mathrm{BRP}_{0}$, which is the mean BRP value of all traverse data within $1 \mathrm{~km}$ of the Siple Dome ice divide,

$$
\frac{\mathrm{BRP}}{\mathrm{BRP}_{0}}=\frac{H_{0}^{2}}{H^{2}} \exp \left[-\frac{2}{L_{a}^{*}}\left(H-H_{0}\right)\right],
$$

where $L_{a}^{*}$ is the depth-averaged attenuation length, $H$ is ice thickness and $H_{0}$ is the mean ice thickness from all the bed reflections within $1 \mathrm{~km}$ of the Siple Dome ice divide. We use a nonlinear least-squares fit to find the value of $L_{a}^{*}$ that minimizes the root-mean-square of the residuals between the data and the fit using (C1). $L_{a}^{*}$ is converted to a depthaveraged attenuation rate using (10).

[79] The application of this method to all of the Siple Dome traverse data within $54 \mathrm{~km}$ of the ice divide is shown in Figure $\mathrm{C} 1$. The revised radar-derived depth-averaged attenuation rate calculated using this method is $25.3 \pm$ $1.1 \mathrm{~dB} \mathrm{~km}^{-1}$, where the uncertainty is the $99 \%$ confidence interval. This value is $0.6 \mathrm{~dB} \mathrm{~km}^{-1}$ less than the value calculated by Winebrenner et al. [2003].

[80] Acknowledgments. J. MacGregor, D. Winebrenner, and H. Conway were supported by National Science Foundation grant OPP 02-29490; K. Matsuoka was supported by National Science Foundation grant ANT 0338151. The Siple Dome density data were provided by the National Snow and Ice Data Center, University of Colorado at Boulder. We thank Associate Editor G. Flowers, R. Jacobel, and an anonymous reviewer for careful and constructive reviews.

\section{References}

Arcone, S. (1995), Numerical studies of the radiation patterns of resistively loaded dipoles, J. Appl. Geophys., 33, 39-52.

Barnes, P., and E. Wolff (2004), Distribution of soluble impurities in cold glacial ice, J. Glaciol., 50, 311-324.

Barnes, P. R.F., E. W. Wolff, R. Mulvaney, R. Udisti, E. Castellano, R. Röthlisberger, and J.-P. Steffensen (2002), Effect of density on electrical conductivity of chemically laden polar ice, J. Geophys. Res., 107(B2), 2029, doi:10.1029/2000JB000080.

Bentley, C., N. Lord, and C. Liu (1998), Radar reflections reveal a wet bed beneath stagnant Ice Stream $\mathrm{C}$ and a frozen bed beneath ridge $\mathrm{BC}$, West Antarctica, J. Glaciol., 44, 149-156.

Bevington, P. (1969), Data Reduction and Error Analysis for the Physical Sciences, 1st ed., 336 pp., McGraw-Hill, New York.

Bogorodsky, V., C. Bentley, and P. Gudmandsen (1985), Radioglaciology, 1st ed., Springer, New York.

Brook, E., J. White, A. Schilla, M. Bender, B. Barnett, J. Severinghaus, K. Taylor, R. Alley, and E. Steig (2005), Timing of milennial-scale climate change at Siple Dome, West Antarctica, during the last glacial period, Quat. Sci. Rev., 24, 1333-1343, doi:10.1016/j.quascirev.2005.02.002.

Camplin, G., and J. Glen (1973), The dielectric properties of HF-doped single crystals of ice, in Physics and Chemistry of Ice, edited by E. Whalley, S. Jones, and L. Gold, pp. 256-261, Royal Soc. Canada, Ottawa.

Castellano, E., S. Becagli, J. Jouzel, A. Migliori, M. Severi, J. Steffensen, R. Traversi, and R. Udisti (2004), Volcanic eruption frequency over the last $45 \mathrm{ky}$ as recorded in Epica-Dome C ice core (East Antarctica) and its relationship with climatic changes, Global Planet. Change, 42, 195-205, doi:10.1016/j.gloplacha.2003.11.007.

Clarke, G., N. Lhomme, and S. Marshall (2005), Tracer transport in the Greenland ice sheet: Three-dimensional isotopic stratigraphy, Quat. Sci. Rev., 24, 155-171, doi:10.01016/j.quascirev.2004.08.021.

Clow, G., R. Slatus, and E. Waddington (1996), A new high-precision borehole-temperature logging system used at GISP2, Greenland and Taylor Dome, Antarctica, J. Glaciol., 42, 576-584.

Corr, H., J. Moore, and K. Nicholls (1993), Radar absorption due to impurities in Antarctic ice, Geophys. Res. Lett., 20, 1071-1074.

Cullen, D., and I. Baker (2001), Observations of impurities in ice, Microbiol. Res. Technol., 55, 198-207.

Dixon, D., P. Mayewski, S. Kaspari, S. Sneed, and M. Handley (2004), A 200 year sub-annual record of sulfate in West Antarctica, from 16 ice cores, Ann. Glaciol., 39, 545-556.

Eisen, O., F. Wilhelms, U. Nixdorf, and H. Miller (2003), Revealing the nature of radar reflections in ice: DEP-based FDTD forward modeling, Geophys. Res. Lett., 30(5), 1218, doi:10.1029/2002GL016403.

Engelhardt, H. (2004), Thermal regime and dynamics of the West Antarctic ice sheet, Ann. Glaciol., 39, 85-92.

Evans, S. (1965), Dielectric properties of ice and snow-A review, J. Glaciol., 5, 773-792.

Fujita, S., and S. Mae (1994), Causes and nature of ice-sheet radio-echo internal reflections estimated from the dielectric properties of ice, Ann. Glaciol., 20, 80-86.

Fujita, S., M. Shiraishi, and S. Mae (1992), Measurement on the dielectric properties of acid-doped ice at $9.7 \mathrm{GHz}$, IEEE Trans. Geosci. Remote Sens., 30, 799-803.

Fujita, S., T. Matsuoka, T. Ishida, K. Matsuoka, and S. Mae (2000), A summary of the complex dielectric permittivity of ice in the megahertz range and its applications for radar sounding of polar ice sheets, in Physics of Ice Core Records, edited by T. Hondoh, pp. 185-212, Hokkaido Univ. Press, Sapporo, Japan.

Fujita, S., N. Azuma, H. Motoyama, T. Kameda, H. Narita, S. Matoba, M. Igarashi, M. Kohno, Y. Fujii, and O. Watanabe (2002), Linear and non-linear relations between the high-frequency-limit conductivity, AC-ECM signals and ECM signals of Dome F Antarctic ice core from a laboratory experiment, Ann. Glaciol., 35, 321-328.

Fujita, S., H. Maeno, and K. Matusoka (2006), Radio-wave depolarization and scattering within ice sheets: A matrix-based model to link radar and ice-core measurements and its application, J. Glaciol., 52, 407-424.

Fukazawa, H., K. Sugiyama, S. Mae, H. Narita, and T. Hondoh (1998), Acid ions at triple junction of Antarctic ice observed by Raman scattering, Geophys. Res. Lett., 25, 2845-2848.

Gades, A., C. Raymond, H. Conway, and R. Jacobel (2000), Bed properties of Siple Dome and adjacent ice streams, West Antarctica, inferred from radio echo-sounding measurements, J. Glaciol., 46, 88-94.

Gogineni, P., T. Chuah, C. Allen, K. Jezek, and R. Moore (1998), An improved coherent radar depth sounder, J. Glaciol., 44, 659-669.

Gow, A., and H. Engelhardt (2000), Preliminary analysis of ice cores from Siple Dome, West Antarctica, in Physics of Ice Core Records, edited by T. Hondoh, pp. 63-82, Hokkaido Univ. Press, Sapporo, Japan.

Gow, A., H. Ueda, and D. Garfield (1968), Antarctic ice sheet: Preliminary results of first core hole to bedrock, Science, 161, 1011-1013. 
Gudmandsen, P. (1971), Electromagnetic probing of ice, in Electromagnetic Probing in Geophysics, edited by J. Wait, pp. 321-348, Golem Press, Boulder, Colo.

Hammer, C., H. Clausen, and C. Langway (1997), 50000 years of recorded global volcanism, Clim. Change, 35, 1-15.

Holland, H. (1978), The Chemistry of the Atmosphere and Oceans, 1st ed., John Wiley, Hoboken, N. J.

Jackson, J. (1975), Classical Electrodynamics, 2nd ed., 848 pp., John Wiley, Hoboken, N. J.

Jacobel, R., and B. Welch (2005), A time marker at 17.5 kyr BP detected throughout West Antarctica, Ann. Glaciol., 41, 47-51.

Jacobel, R., T. Scambos, C. Raymond, and A. Gades (1996), Changes in the configuration of ice stream flow from the West Antarctic ice sheet, J. Geophys. Res., 101, 5499-5504.

Johari, G., and P. Charette (1975), The permittivity and attenuation in polycrystalline and single-crystal ice Ih at 35 and $60 \mathrm{MHz}, J$. Glaciol., 14, 293-303.

Kovacs, A., A. Gow, and R. Morey (1995), The in-situ dielectric constant of polar firn revisited, Cold Reg. Sci. Technol., 23, 245-256.

Legrand, M., and M. de Angelis (1996), Light carboxylic acids in Greenland ice: A record of past forest fires and vegetation emissions from the boreal zone, J. Geophys. Res., 101, 4129-4145.

Legrand, M., and R. Delmas (1988), Formation of $\mathrm{HCl}$ in the Antarctic atmosphere, J. Geophys. Res., 93, 7153-7168.

Legrand, M., and P. Mayewski (1997), Glaciochemistry of polar ice cores: A review, Rev. Geophys., 35, 219-243.

Legrand, M., C. Lorius, N. Barkov, and V. Petrov (1988), Vostok (Antarctica) ice core: Atmospheric chemistry changes over the last climatic cycle (160,000 years), Atmos. Environ., 22, 317-331.

Matsuoka, K., S. Fujita, T. Matsuoka, T. Ishida, T. Hondoh, and S. Mae (1996), Measurements of the complex permittivity of acid-doped ice from $1 \mathrm{kHz}$ to $30 \mathrm{MHz}$ - New data set for developing ice radar and dielectric analysis of ice cores, in Proceedings of the NIPR Symposium on Polar Meteorology and Glaciology, vol. 10, pp. 25-35, Natl. Inst. Pol. Res., Tokyo, Japan.

Matsuoka, K., H. Maeno, S. Uratsuka, S. Fujita, T. Furukawa, and O. Watanabe (2002), A ground-based multi-frequency ice-penetrating radar system, Ann. Glaciol., 34, 171-176.

Matsuoka, T., S. Fujita, and S. Mae (1997a), Dielectric properties of ice containing ionic impurities at microwave frequencies, J. Phys. Chem. B, $101,6219-6222$.

Matsuoka, T., S. Fujita, S. Morishima, and S. Mae (1997b), Precise measurement of dielectric anisotropy in Ice Ih at $39 \mathrm{GHz}$, J. Appl. Phys., 81, 2344-2348

Mayewski, P., M. Twickler, and S. Whitlow (1995), The Siple Dome ice core-Reconnaissance glaciochemistry, Antarct. J. U.S., 30, 85-87.

Miners, W. D., E. W. Wolff, J. C. Moore, R. Jacobel, and L. Hempel (2002), Modeling the radio echo reflections inside the ice sheet at Summit, Greenland, J. Geophys. Res., 107(B8), 2172, doi:10.1029/2001JB000535.

Moore, J., and S. Fujita (1993), Dielectric properties of ice containing acid and salt impurity at microwave and low frequencies, J. Geophys. Res., 98, 9769-9780.

Moore, J., R. Mulvaney, and J. Paren (1989), Dielectric stratigraphy of ice: A new technique for determining total ionic concentrations in polar ice cores, Geophys. Res. Lett., 16, 1177-1180.

Moore, J., J. Paren, and H. Oerter (1992a), Sea salt dependent electrical conduction in polar ice, J. Geophys. Res., 97, 19,803-19,812.

Moore, J., E. Wolff, H. Clausen, and C. Hammer (1992b), The chemical basis for the electrical stratigraphy of ice, J. Geophys. Res., 97, 18871896.

Moore, J., E. Wolff, H. Clausen, C. Hammer, M. Legrand, and K. Fuhrer (1994), Electrical response of the Summit-Greenland ice core to ammonium, sulphuric acid, and hydrochloric acid, Geophys. Res. Lett., 21, $565-568$.
Mulvaney, R., E. Wolff, and K. Oates (1988), Sulphuric acid at grain boundaries in Antarctic ice, Nature, 331, 247-249.

Nereson, N., and E. Waddington (2002), Isochrones and isotherms beneath migrating ice divides, J. Glaciol., 48, 95-108.

Nereson, N., C. Raymond, R. Jacobel, and E. Waddington (2000), The accumulation pattern across Siple Dome, West Antarctica, inferred from radar-detected internal layers, J. Glaciol., 46, 75-87.

Paren, J. (1981), Reflection coefficient at a dielectric interface, J. Glaciol., 27, 203-204.

Paterson, W. (1994), The Physics of Glaciers, 3rd ed., 481 pp., Elsevier, New York.

Peters, M. E., D. D. Blankenship, and D. L. Morse (2005), Analysis techniques for coherent airborne radar sounding: Application to West Antarctic ice streams, J. Geophys. Res., 110, B06303, doi:10.1029/2004JB003222.

Petrenko, V., and R. Whitworth (1999), Physics of Ice, 1st ed., Oxford Univ. Press, New York.

Rankin, A., V. Auld, and E. Wolff (2000), Frost flowers as a source of fractionated sea salt aerosol in the polar regions, Geophys. Res. Lett., 27, $3469-3472$.

Rankin, A., E. Wolff, and R. Mulvaney (2004), A reinterpretation of sea-salt records in Greenland and Antarctic ice cores?, Ann. Glaciol., 39, 276-282.

Rasmussen, L. (1986), Refraction correction for radio-echo soundings of ice overlain by firn, J. Glaciol., 32, 192-194.

Saltzman, E. S., I. Dioumaeva, and B. D. Finley (2006), Glacial/interglacial variations in methanesulfonate (MSA) in the Siple Dome ice core, West Antarctica, Geophys. Res. Lett., 33, L11811, doi:10.1029/2005GL025629.

Shabtaie, S., I. Whillans, and C. Bentley (1987), The morphology of ice streams A, B, and C, West Antarctic, and their environs, J. Geophys. Res., 92, 8865-8883.

Sugiyama, K., S. Fujita, H. Narita, S. Mae, T. Hondoh, Goto-K. Azuma, D. Fisher, and R. Koerner (2000), Measurement of electrical conductance in ice cores by AC-ECM method, in Physics of Ice Core Records, edited by T. Hondoh, pp. 173-184, Hokkaido Univ. Press, Sapporo, Japan.

Takei, I., and N. Maeno (1987), Electric characteristics of point defects in HCl-doped ice, J. Phys., 48, 121-126.

Taylor, K., and R. Alley (2004), Two-dimensional electrical stratigraphy of the Siple Dome (Antarctica) ice core, J. Glaciol., 50, 231-235.

Wettlaufer, J. (1999), Impurity effects in the premelting of ice, Phys. Rev. Lett., 82, 2516-2519.

Winebrenner, D., B. Smith, G. Catania, H. Conway, and C. Raymond (2003), Radio-frequency attenuation beneath Siple Dome, West Antarctica from wide-angle and profiling radar observations, Ann. Glaciol., 37, 226232.

Wolff, E. (2000), Electrical stratigraphy of polar ice cores: Principles, methods and findings, in Physics of Ice Core Records, edited by T. Hondoh, pp. 155-171, Hokkaido Univ. Press, Sapporo, Japan.

Wolff, E., and J. Paren (1984), A two-phase model of electrical conduction in polar ice sheets, J. Geophys. Res., 89, 9433-9438.

Wolff, E., J. Moore, H. Clausen, C. Hammer, J. Kipfstuhl, and K. Fuhrer (1995), Long-term changes in the acid and salt concentrations of the Greenland Ice Core Project ice core from electrical stratigraphy, J. Geophys. Res., 100, 16,249-16,263.

Wolff, E., W. Miners, J. Moore, and J. Paren (1997), Factors controlling the electrical conductivity of ice from the polar regions-A summary, J. Phys. Chem. B, 101, 6090-6094.

G. D. Clow, U.S. Geological Survey, Lakewood, CO 80225, USA.

H. Conway, J. A. MacGregor, and K. Matsuoka, Department of Earth and Space Sciences, University of Washington, Box 351310, Seattle, WA 98195, USA. (joemac@u.washington.edu)

P. A. Mayewski, Climate Change Institute, University of Maine at Orono, Orono, ME 04473, USA.

D. P. Winebrenner, Polar Science Center, Applied Physics Laboratory, Box 355640, University of Washington, Seattle, WA 98195, USA. 